\title{
BMJ Open Do school closures and school reopenings affect community transmission of COVID-19? A systematic review of observational studies
}

\author{
Sebastian Walsh (D) , ${ }^{1}$ Avirup Chowdhury (D) , ${ }^{2}$ Vickie Braithwaite (D) , ${ }^{2}$ \\ Simon Russell, ${ }^{3}$ Jack Michael Birch (1) , ${ }^{2}$ Joseph L Ward, ${ }^{3}$ Claire Waddington, ${ }^{4}$ \\ Carol Brayne, ${ }^{1}$ Chris Bonell (D) , ${ }^{5}$ Russell M Viner (D) , ${ }^{3}$ Oliver T Mytton (1) ${ }^{2}$
}

To cite: Walsh S, Chowdhury A, Braithwaite V, et al. Do school closures and school reopenings affect community transmission of COVID-19? A systematic review of observational studies. BMJ Open 2021;11:e053371. doi:10.1136/ bmjopen-2021-053371

- Prepublication history and additional supplemental material for this paper are available online. To view these files, please visit the journal online (http://dx.doi.org/10.1136/ bmjopen-2021-053371).

Received 11 May 2021 Accepted 16 July 2021

Check for updates

(C) Author(s) (or their employer(s)) 2021. Re-use permitted under CC BY-NC. No commercial re-use. See rights and permissions. Published by BMJ.

For numbered affiliations see end of article.

Correspondence to Dr Sebastian Walsh; sjw261@medschl.cam.ac.uk

\section{ABSTRACT}

Objectives To systematically reivew the observational evidence of the effect of school closures and school reopenings on SARS-CoV-2 community transmission. Setting Schools (including early years settings, primary schools and secondary schools).

Intervention School closures and reopenings. Outcome measure Community transmission of SARSCoV-2 (including any measure of community infections rate, hospital admissions or mortality attributed to COVID-19).

Methods On 7 January 2021, we searched PubMed, Web of Science, Scopus, CINAHL, the WHO Global COVID-19 Research Database, ERIC, the British Education Index, the Australian Education Index and Google, searching title and abstracts for terms related to SARS-CoV-2 AND terms related to schools or non-pharmaceutical interventions (NPIs). We used the Cochrane Risk of Bias In Nonrandomised Studies of Interventions tool to evaluate bias. Results We identified 7474 articles, of which 40 were included, with data from 150 countries. Of these, 32 studies assessed school closures and 11 examined reopenings. There was substantial heterogeneity between school closure studies, with half of the studies at lower risk of bias reporting reduced community transmission by up to $60 \%$ and half reporting null findings. The majority ( $n=3$ out of 4 ) of school reopening studies at lower risk of bias reported no associated increases in transmission.

Conclusions School closure studies were at risk of confounding and collinearity from other nonpharmacological interventions implemented around the same time as school closures, and the effectiveness of closures remains uncertain. School reopenings, in areas of low transmission and with appropriate mitigation measures, were generally not accompanied by increasing community transmission. With such varied evidence on effectiveness, and the harmful effects, policymakers should take a measured approach before implementing school closures; and should look to reopen schools in times of low transmission, with appropriate mitigation measures.

\section{Strengths and limitations of this study}

While the role of non-pharmaceutical interventions as a whole in limiting community spread of SARSCoV-2 is beyond doubt, the specific role of school closures is less clear because of the smaller role that children play in transmission of the disease.

- This is the first systematic review of the empirical evidence from the COVID-19 pandemic of the effectiveness of school closures and reopenings on community transmission of SARS-CoV-2.

- We include data from 150 countries, investigating both school closures and school reopenings.

- We were unable to meta-analyse due to data heterogeneity.

\section{INTRODUCTION}

School closures have been a common strategy to control the spread of SARS-CoV-2 during the COVID-19 pandemic. By 2 April 2020, 172 nations had enacted full closures or partial 'dismissals', affecting nearly 1.5 billion children. ${ }^{1}$ As cases of COVID-19 started to fall, many countries looked to reopen schools, often with significant mitigation measures in place. $^{2}$ Over the northern hemisphere winter of 2020-21, many countries again closed schools with the aim of controlling a resurgence of cases. School closures have substantial negative consequences for children's well-being and education, which will impact on life chances and long-term health. ${ }^{34}$ Closures exacerbate existing inequalities, with greater impacts on children from socioeconomically deprived backgrounds because those from higher income families have better opportunities for remote learning.

The role of non-pharmaceutical interventions (NPIs) collectively in limiting 
community spread is established. However, the specific contribution of school closures remains unclear. Observational studies suggest that school-aged children, particularly teenagers, play a role in transmission to peers and bringing infection into households, ${ }^{5}$ although the relative importance compared with adults remains unclear. ${ }^{6}$ Younger children appear less susceptible to infection and may play a smaller role in community transmission, compared with older children and adults. ${ }^{7}$ Although some modelling studies have suggested that school closures can reduce SARS-CoV-2 community transmission, ${ }^{8}$ others disagree. $^{9} 10$

A rapid systematic review published in April 2020 found a small number of studies of the effectiveness of school closures in controlling the spread of COVID$19 .{ }^{11}$ However, this review was undertaken very early in the pandemic and included no observational data on SARS-CoV-2. Since then many studies on the effects of closing or reopening schools on SARS-CoV-2 community transmission have been published, but there has been no systematic review of these studies. A clearer understanding of the impact of school closures and reopenings on community transmission is essential to aid policymakers in deciding if and when to implement school closures in response to rising virus prevalence, and when it is prudent to reopen schools. Here, we synthesise the observational evidence of the impact of closing or reopening schools on community transmission of SARS-CoV-2.

\section{METHODS}

The study protocol for this systematic review is registered on PROSPERO (ID: CRD42020213699).

\section{Inclusion and exclusion criteria}

We included any empirical study which reported a quantitative estimate of the effect of school closure or reopening on community transmission of SARS-CoV-2. We considered 'school' to include early years settings (eg, nurseries or kindergartens), primary schools and secondary schools, but excluded further or higher education (eg, universities). Community transmission was defined as any measure of community infection rate, hospital admissions or mortality attributed to COVID-19. We included studies published in 2020 or 2021 only. We included preprints, peer-reviewed and grey literature. We did not apply any restriction on language, but all searches were undertaken in English. We excluded prospective modelling studies and studies in which the assessed outcome was exclusively transmission within the school environment rather than the wider community.

\section{Search strategy}

We searched PubMed, Web of Science, Scopus, CINAHL, the WHO Global COVID-19 Research Database (including medRxiv and SSRN), ERIC, the British Education Index and the Australian Education Index, searching title and abstracts for terms related to SARS-CoV-2 AND terms related to schools or NPIs. To search the grey literature, we searched Google. We also included papers identified through professional networks. Full details of the search strategy are included in online supplemental appendix A. Searches were undertaken first on 12 October 2020 and updated on 7 January 2021.

\section{Data extraction and risk of bias assessment}

Article titles and abstracts were imported into the Rayyan QCRI webtool. ${ }^{12}$ Two reviewers independently screened titles and abstracts, retrieved full texts of potentially relevant articles and assessed eligibility for inclusion.

Two reviewers independently extracted data and assessed risk of bias. Data extraction was performed using a pre-agreed extraction template which collected information on publication type (peer-reviewed or preprint), country, study design, exposure type (school closure or reopening), setting type (primary or secondary), study period, unit of observation, confounders adjusted for, other NPIs in place, analysis method, outcome measure and findings. We used the Cochrane Risk of Bias In Nonrandomised Studies of Interventions tool ${ }^{13}$ to evaluate bias.

Discrepancies were resolved by discussion in the first instance and by a third reviewer where necessary.

\section{Data synthesis}

Given the heterogeneous nature of the studies, prohibiting meta-analysis, a narrative synthesis was conducted. Schools often reopened with significant COVID-19 infection prevention and control measures in place, meaning that the effect of lifting restrictions may have been different from the effect of imposing them. We therefore considered the studies of school closures and school reopenings separately. We also aimed to evaluate differential effects for primary and secondary schools if data allowed.

\section{Patient and public involvement}

There was no patient or public involvement in this study.

\section{RESULTS}

We identified 7474 studies (figure 1). After removing 2339 duplicates, 5135 unique records were screened for inclusion. We excluded 4842 records at the title or abstract stage, leaving 293 records for full-text review. Of these, $40^{14-53}$ met the inclusion criteria.

\section{Description of studies}

Included studies are described in table 1, grouped by exposure type and study design. Of these, 32 studies $^{14} 15$ 18-21 232426 29-40 42-44 46-53 reported the effect of school closures on community transmission of

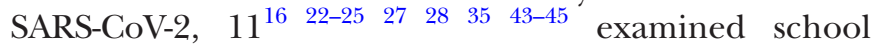
reopening and $3^{161741}$ investigated the effect of school holidays. Some studies considered more than one exposure. All studies used data from national government sources or international data repositories. A total of 15 


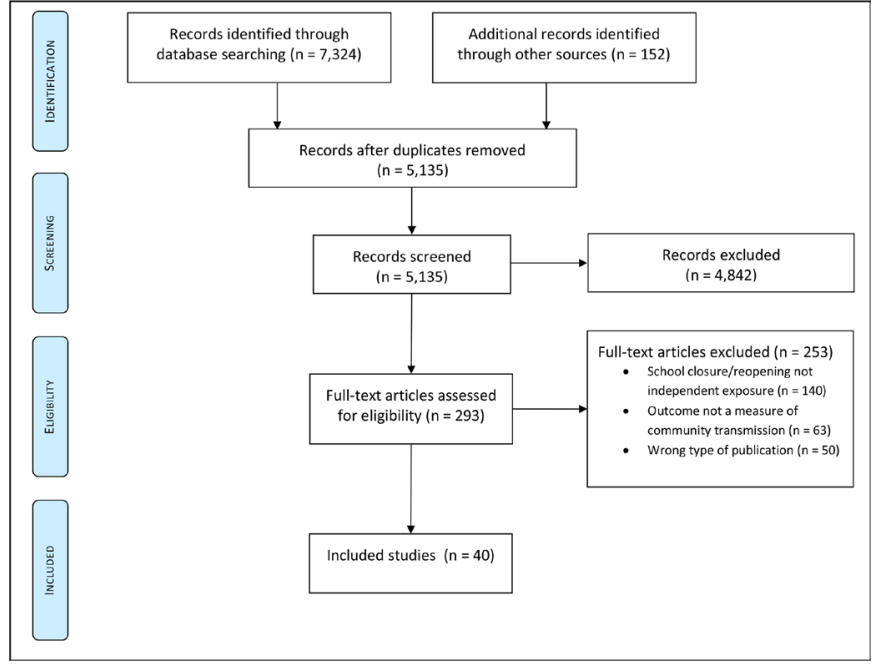

Figure 1 Preferred Reporting Items for Systematic Reviews and Meta-Analyses flow diagram.

studies were from peer-reviewed journals, while 24 studies were from preprint servers and 1 study was a conference abstract.

All studies were ecological in nature, that is, the unit of analysis was national or regional. Of the school closure studies, 13 reported data from a single country or region (the USA $(n=10),{ }^{14} 19-2133374247-49$ Italy $(n=1),{ }^{23}$ Japan $(n=1)^{29}$ and Switzerland $\left.(n=1)^{43}\right) ; 4$ reported discrete estimates for several countries 264453 and 15 studies pooled data from multiple countries (globally $(n=8),{ }^{31} 34-3639465051$ Europe only $(n=2),{ }^{24} 30$ Europe and other high-income countries $\left.(n=5)^{15} 18324052\right)$. The studies on school reopening generally reported on single countries (Germany $(\mathrm{n}=2),{ }^{22} 28$ USA $(\mathrm{n}=1),{ }^{25}$ Switzerland $(\mathrm{n}=1),{ }^{43}$ Belgium $(\mathrm{n}=1),{ }^{27}$ Israel $(\mathrm{n}=1),{ }^{45}$ Italy $\left.(\mathrm{n}=1)^{23}\right)$, but one reported discrete estimates for three countries (Denmark, Germany and Norway), ${ }^{44}$ two pooled data from multiple countries globally ${ }^{1635}$ and one pooled data from multiple European countries. ${ }^{24}$ Of the three school holiday studies, one reported on Germany, ${ }^{41}$ one pooled data from 24 countries globally ${ }^{16}$ and one pooled data from multiple European countries. ${ }^{17}$

The majority of studies $(n=24)$ did not specify the type of school setting being studied. However, eight studies specified that they were reporting on primary and secondary schools only, ${ }^{1416181927293749}$ and six additionally include early years settings. ${ }^{22-24} 444548$ The two remaining studies used the date of primary school $(n=1)^{15}$ or secondary school $(n=1)^{43}$ closure as their exposure date, but did not indicate this was temporally distinct from closure of the other setting. Very few studies reported independent effect sizes for different setting types: two closure studies $^{2448}$ and four reopening studies. ${ }^{16222444}$

Studies that specifically sought to estimate an effect of school closure policy on SARS-CoV-2 transmission included eight school closure studies, ${ }^{14} 23293237384244$ six school reopening studies 222325284445 and three school holiday studies. The remaining studies primarily sought to estimate the effect of NPIs (but reported an independent estimate for schools, alongside estimates for other NPIs within their analysis).

The studies used different analytic approaches: regression models $(\mathrm{n}=24),{ }^{141719-21} 252628303133353639-424446484951-53$ Bayesian modelling $(\mathrm{n}=3),{ }^{15} 1847$ comparison to a synthetic control group $(\mathrm{n}=4),{ }^{24343844}$ machine learning approaches $(\mathrm{n}=2),{ }^{43}{ }^{50}$ time series analysis $(\mathrm{n}=1)^{29}$ and visual representation of changes in transmission over time compared against the timing of school policy interventions, with or without formal statistical analysis $(n=4){ }^{16} 223745 \mathrm{We}$ identified three study designs used to estimate the effect of school closures: pooled multiple-area before-after comparisons (n=22), 14 15 18-21 242630 32-36 394042 46-50 withinarea before-after comparisons $(n=7) 23293738434453$ and pooled multiple-area comparisons of interventions in place at a fixed time point $(n=3) .{ }^{31} 5152$

In most instances of school closures, particularly in European countries, other NPIs were introduced at or around the same time. Some studies dealt with this at the design stage, choosing to study places where school closures were done in (relative) isolation ${ }^{37}$ and some at the analytical stage (typically by undertaking regression and having multiple comparator countries). Some studies did not appear to have a mechanism in place to deal with this potential confounding. ${ }^{32} 404452$ Studies which pooled data from multiple areas also adjusted for other potential confounders, such as population factors (eg, proportion of population aged $\geq 65$ years, population density) and SARS-CoV-2 testing regimes.

Among school closure studies, $18^{1415192024262931-34373942-445051}$ reported effects on

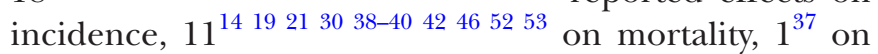
hospital admissions and mortality and $8^{1821233536434748}$ on an estimate of the effective Reproductive number (R) (derived from incidence and/or mortality data). Of the school reopening studies, six reported effects on incidence, ${ }^{162224284445}$ two on hospitalisations ${ }^{2544}$ and four on R. ${ }^{23273543}$ Two school holiday studies reported an effect on incidence, ${ }^{1641}$ while the other reported on mortality. ${ }^{17}$ The assumed lag period from school policy changes to changes in incidence rate varied between 7 and 20 days, with longer time periods of 26-28 days generally assumed for mortality.

Risk of bias is summarised in table 2. Of the school closure studies, 14 were found to be at moderate risk of bias, ${ }^{14} \quad 15 \quad 18-20 \quad 24 \quad 26 \quad 30 \quad 35-37 \quad 46-48 \quad 14$ at serious risk $^{21} 23293133343839424349-5153$ and 4 at critical risk of bias. $^{32} 404452$ Of the school reopening studies, four were found to be at moderate risk, ${ }^{24} 252835$ four at serious risk $^{23274344}$ and three at critical risk of bias. ${ }^{16245}$ The school holiday studies were found to be at moderate $(\mathrm{n}=1),{ }^{41}$ serious $(\mathrm{n}=1){ }^{17}$ or critical $(\mathrm{n}=1)^{16}$ risk of bias.

There was significant heterogeneity in the study findings (table 3): 17 studies $^{1424313234-384042-4448-51}$ reported that closing schools was associated with a reduction in transmission rates; $9^{1518} 20232629303947$ found no association 


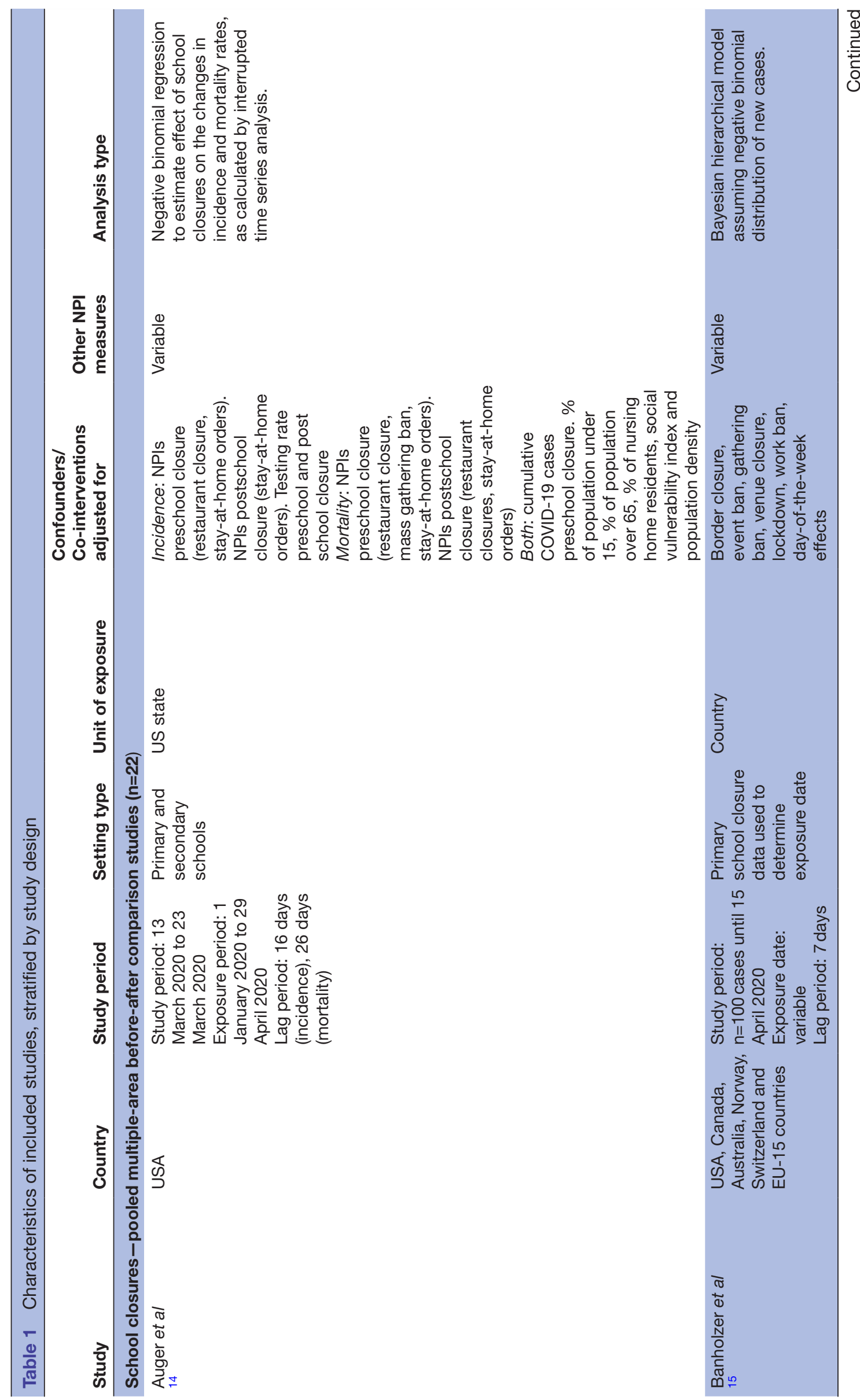




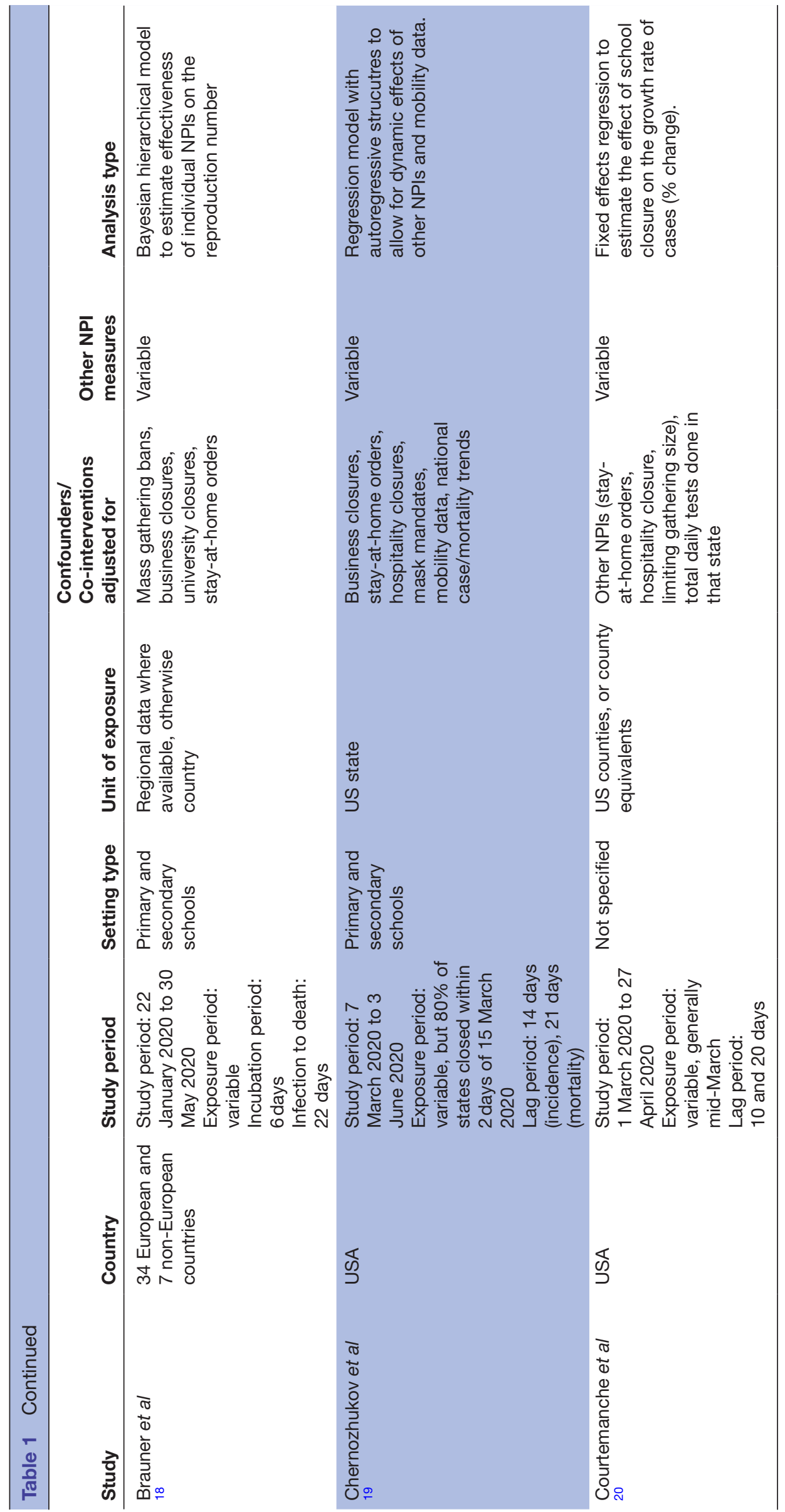




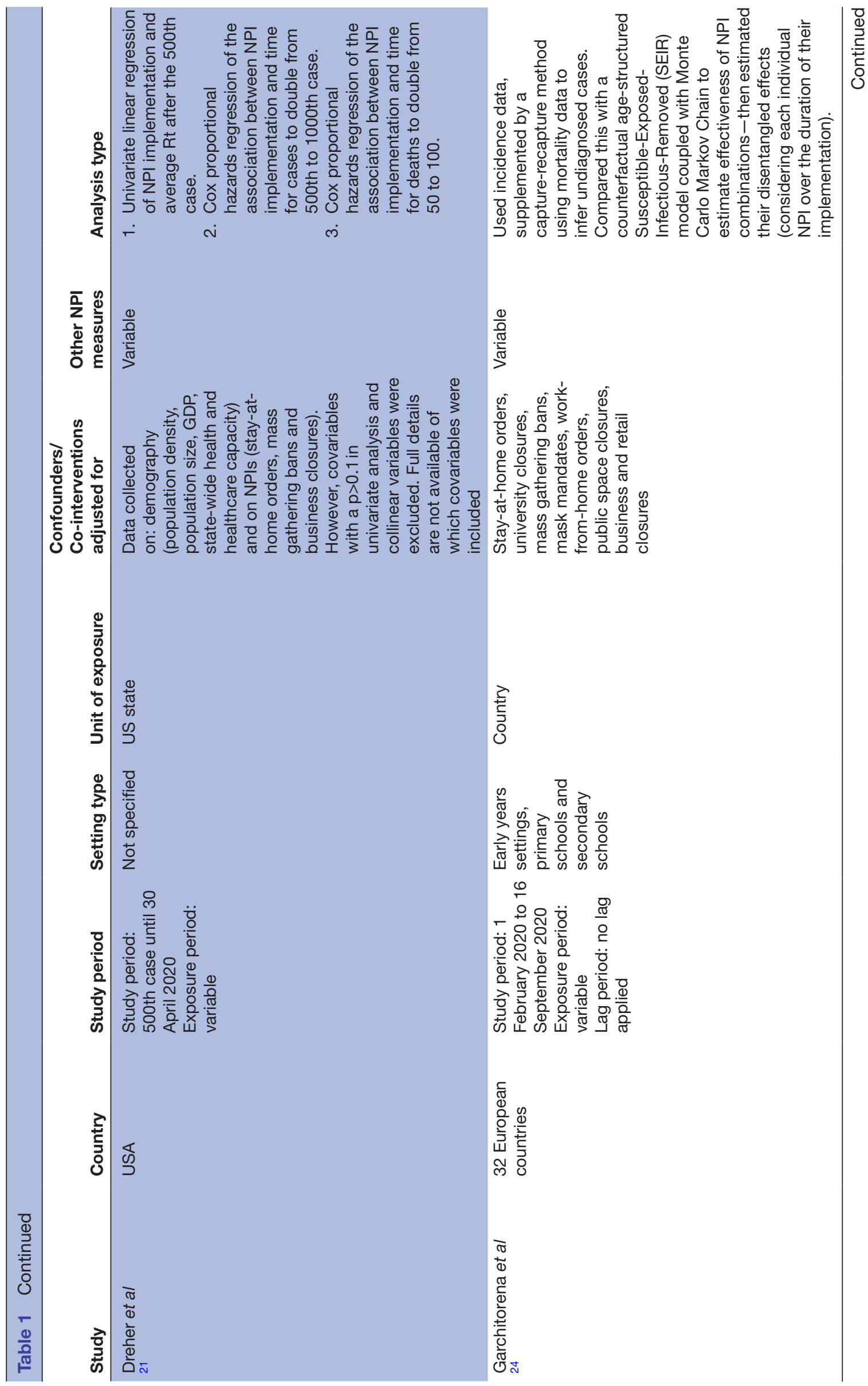




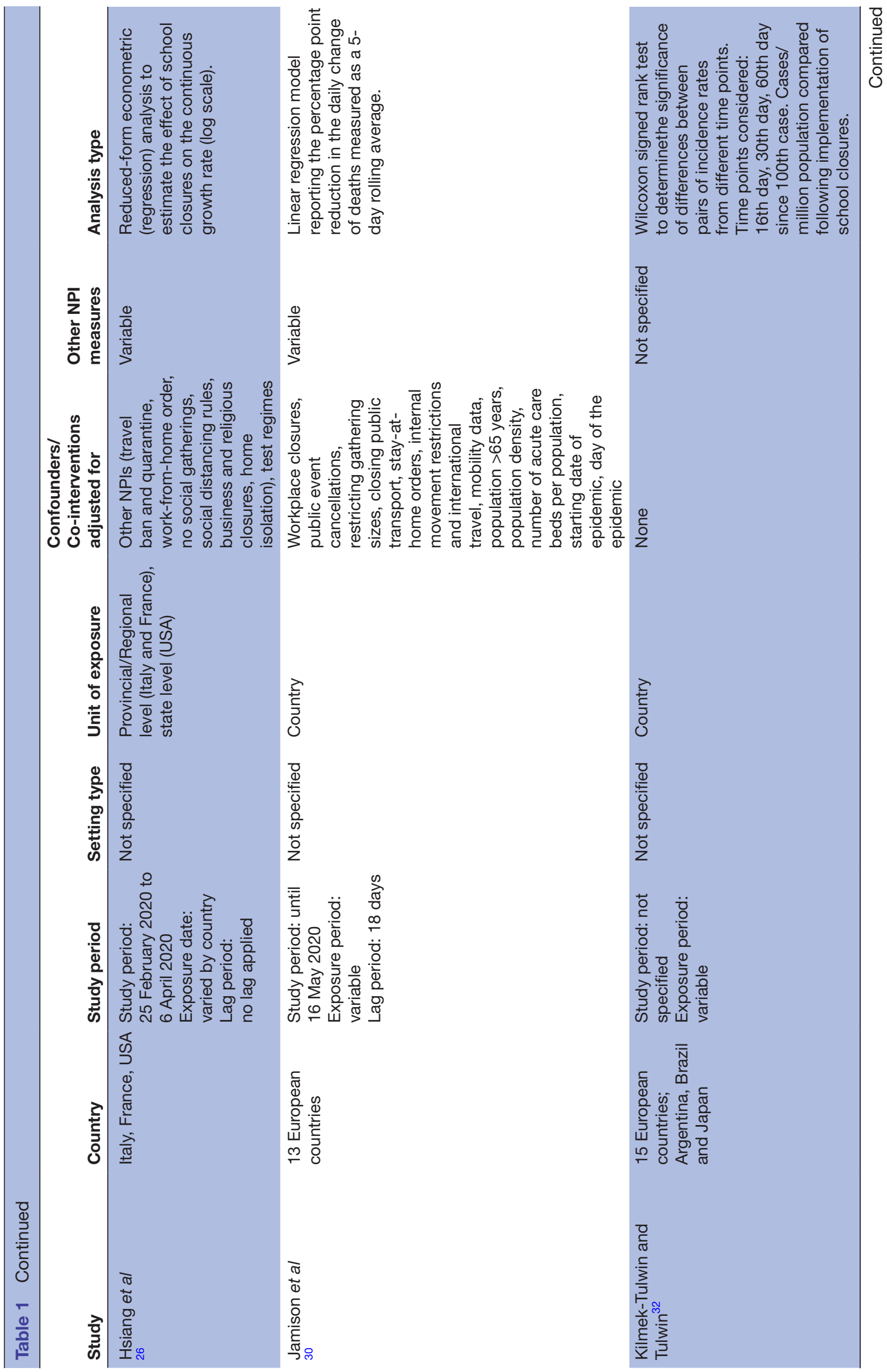




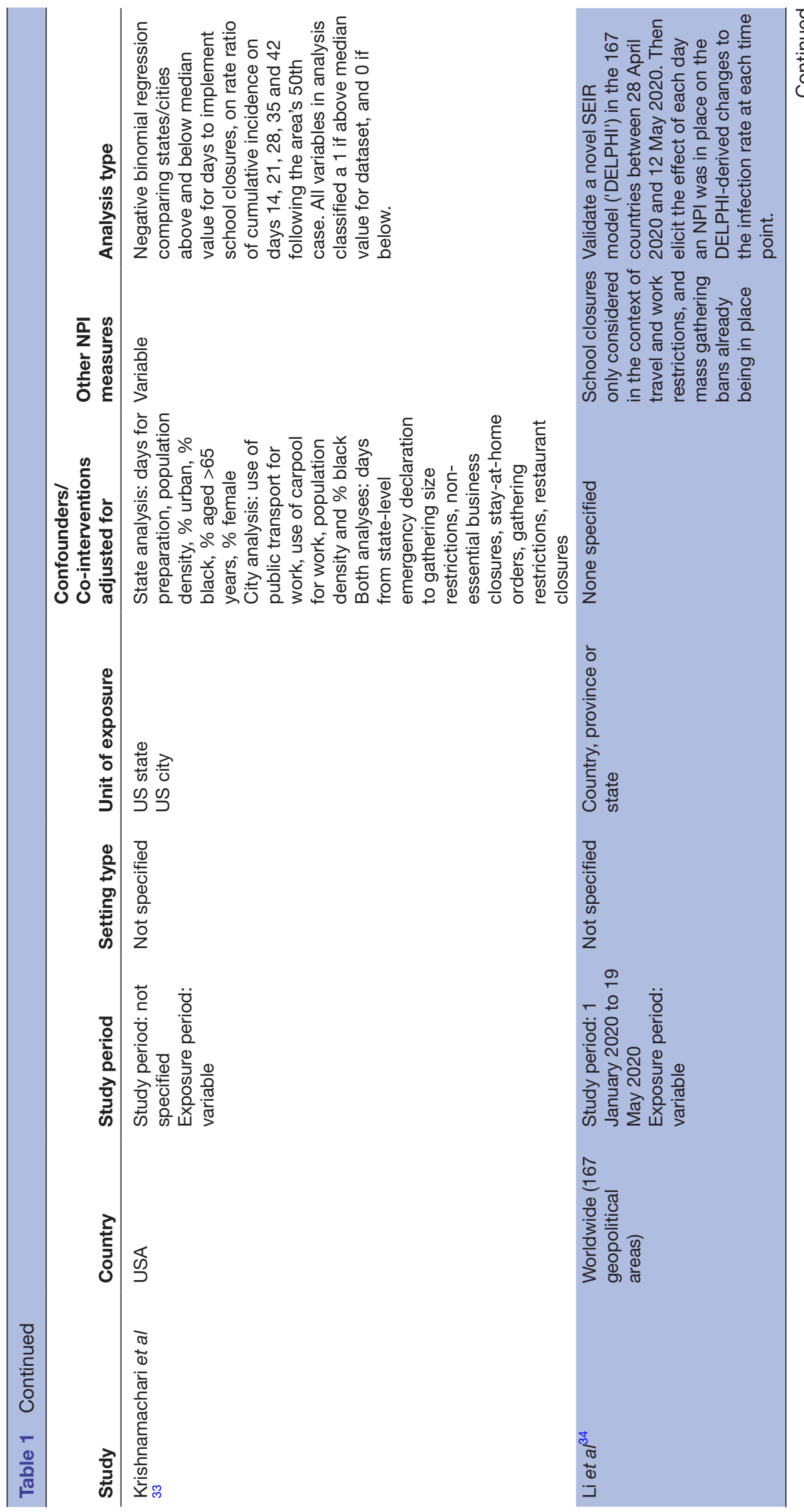




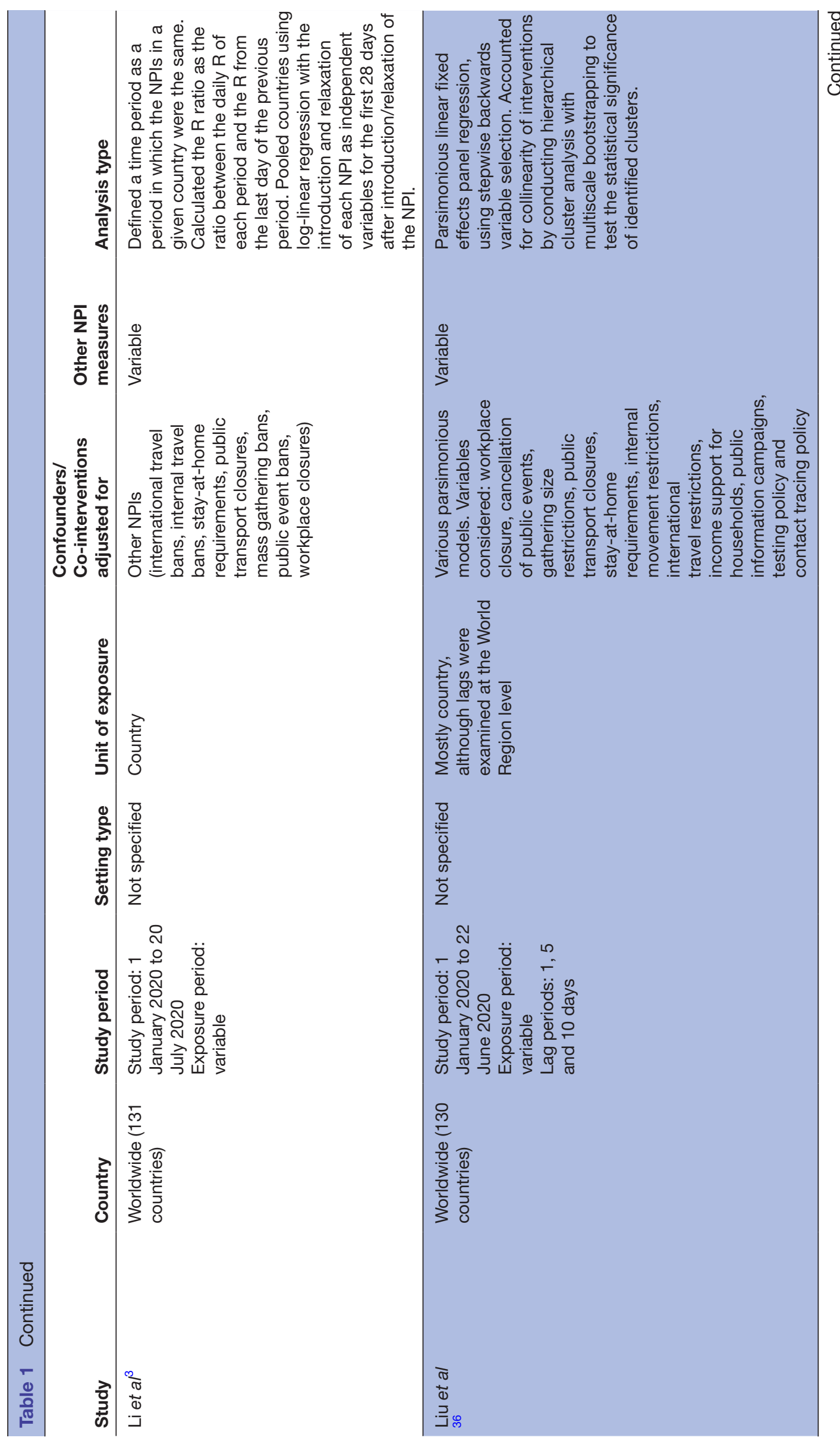




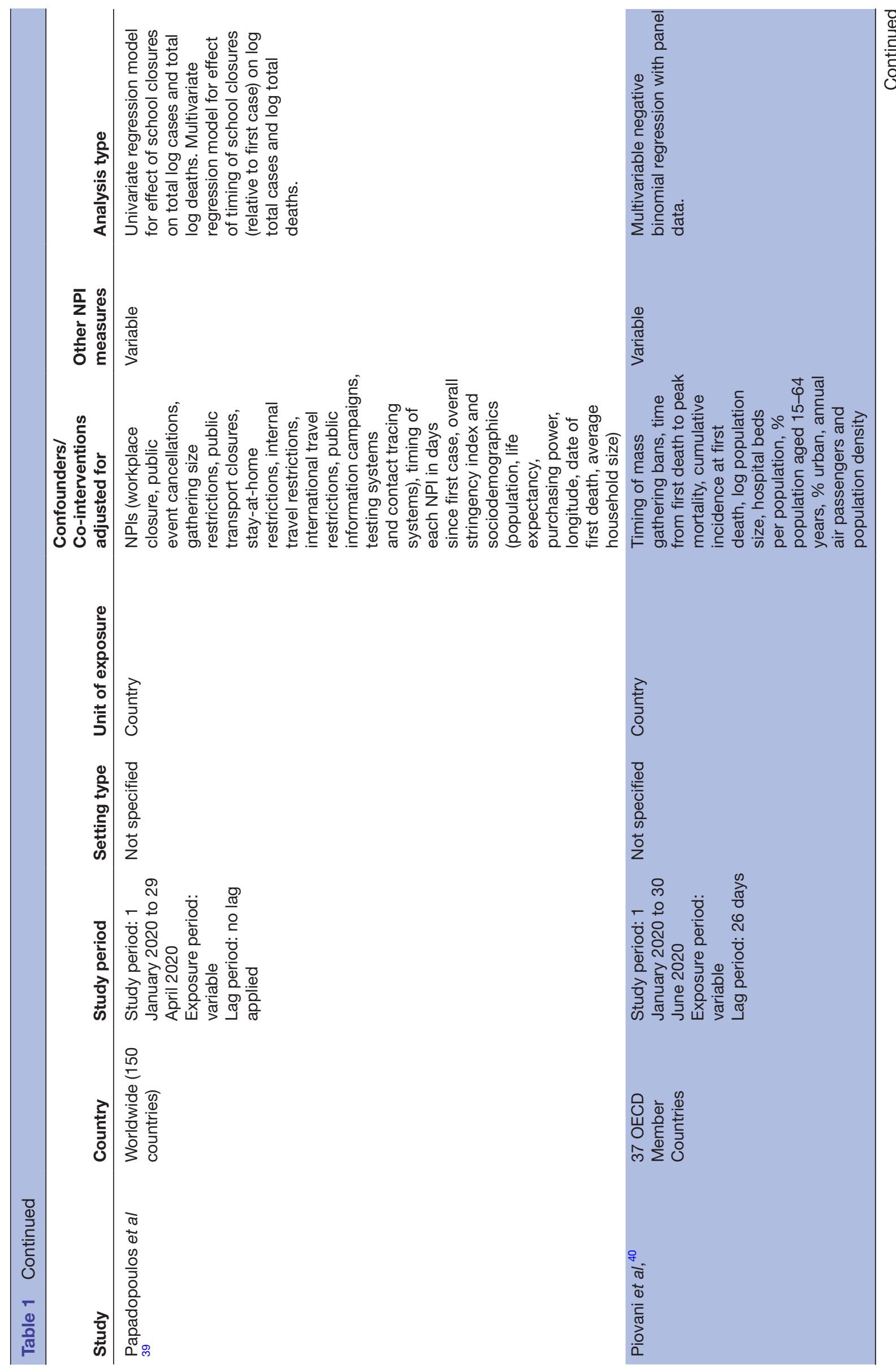









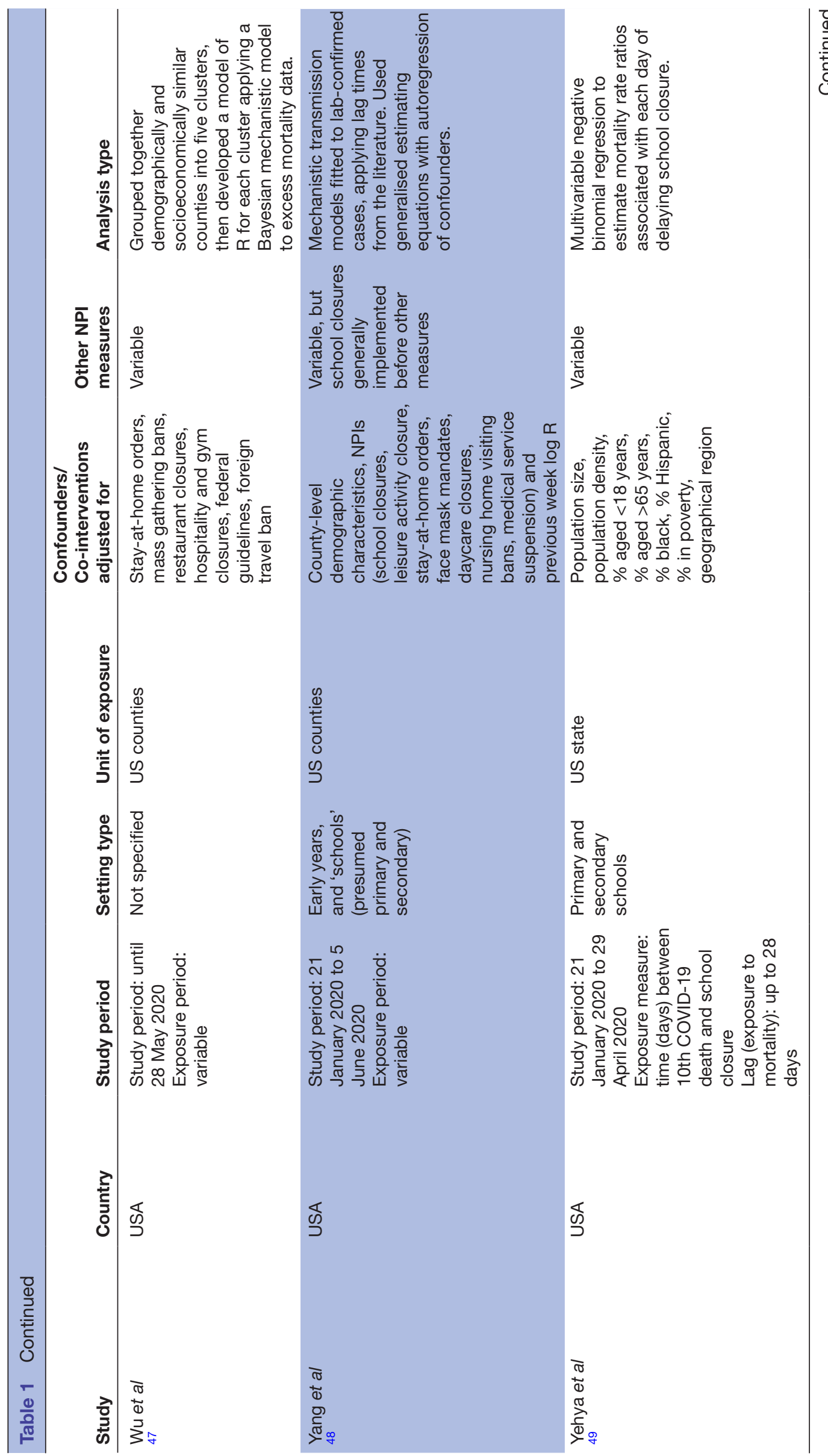



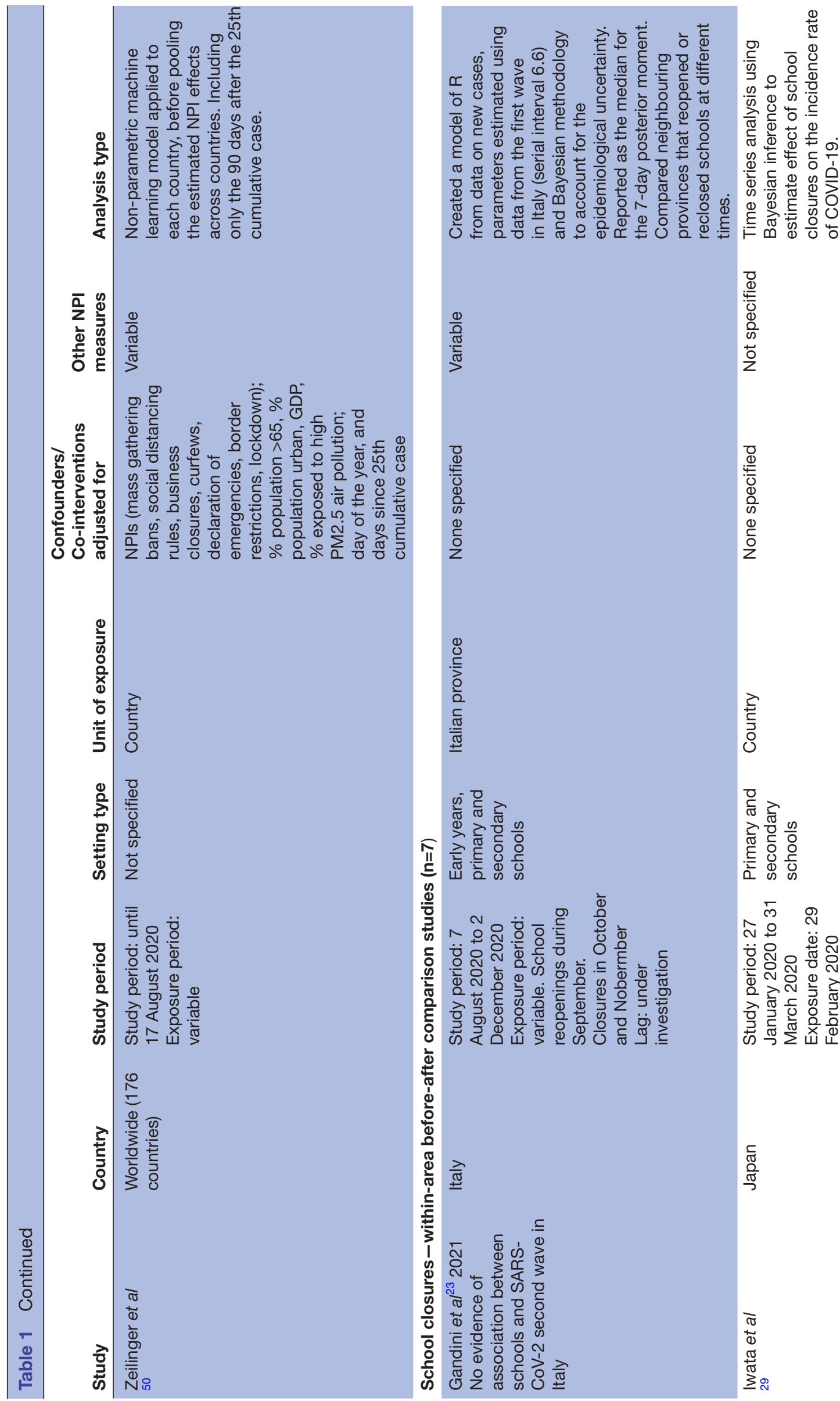

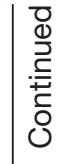

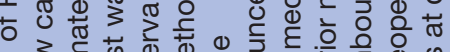

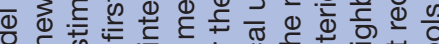

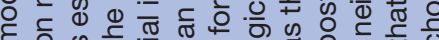
ส

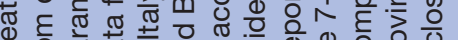

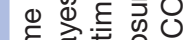
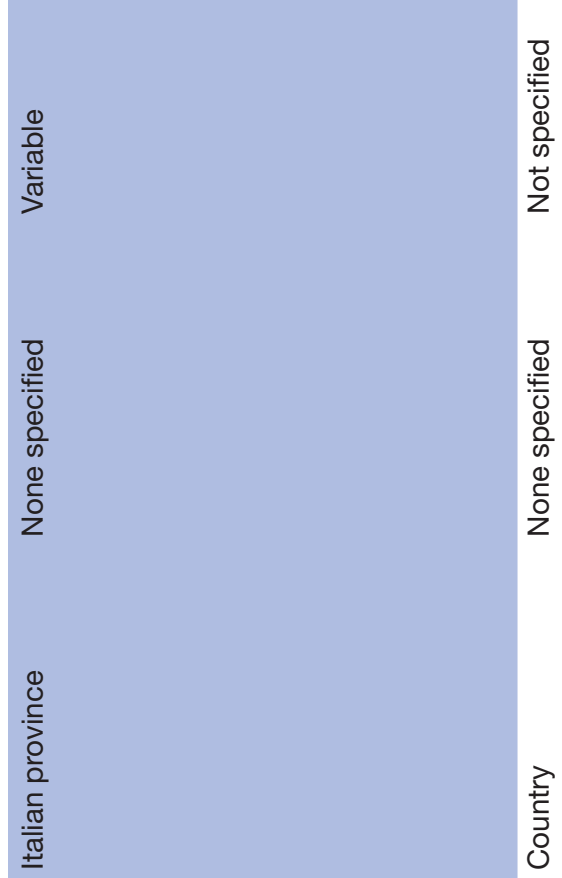

藏
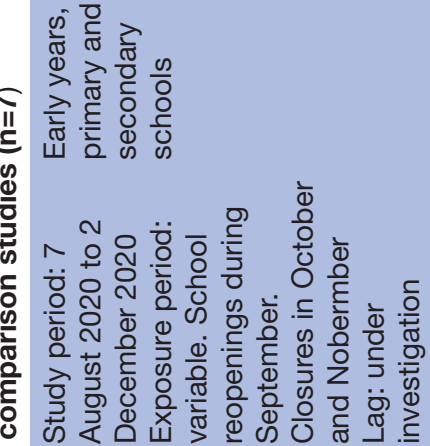

辛
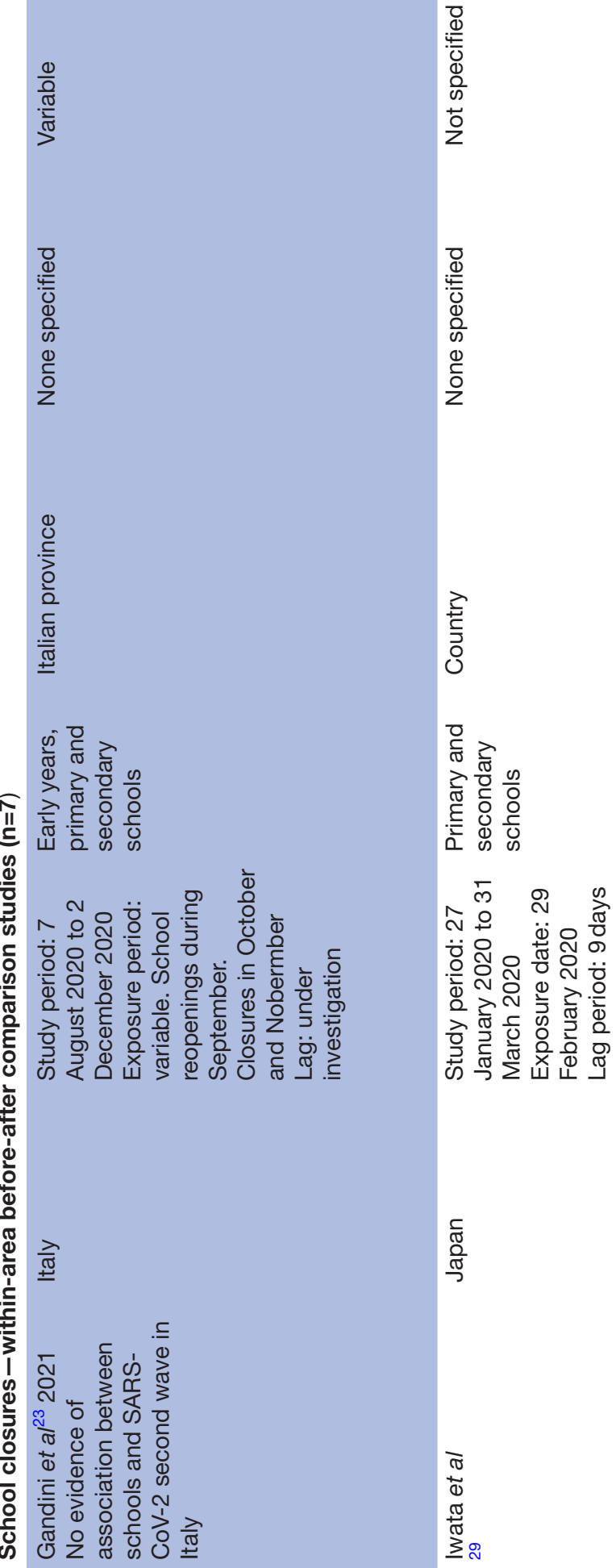

त्र

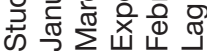

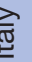

$\frac{\sqrt{\pi}}{\frac{\pi}{\pi}}$
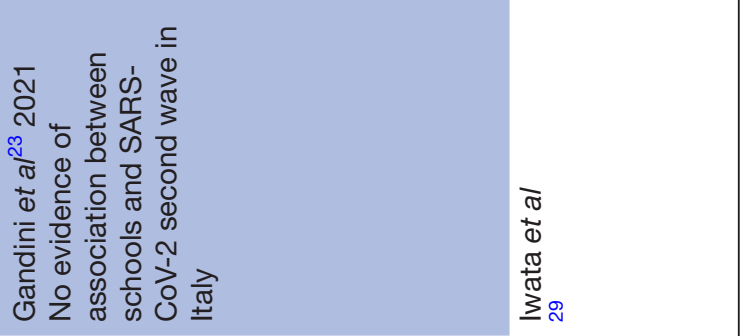







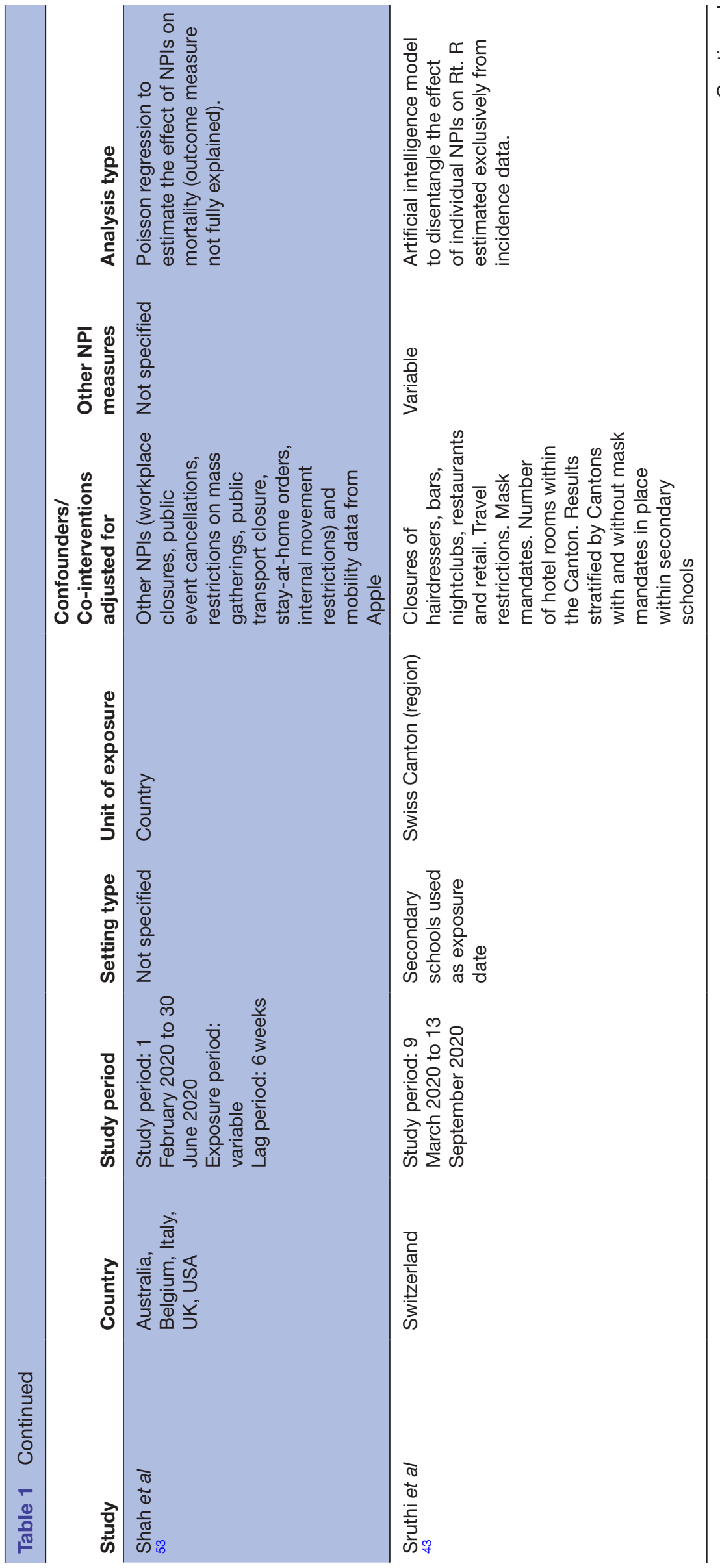




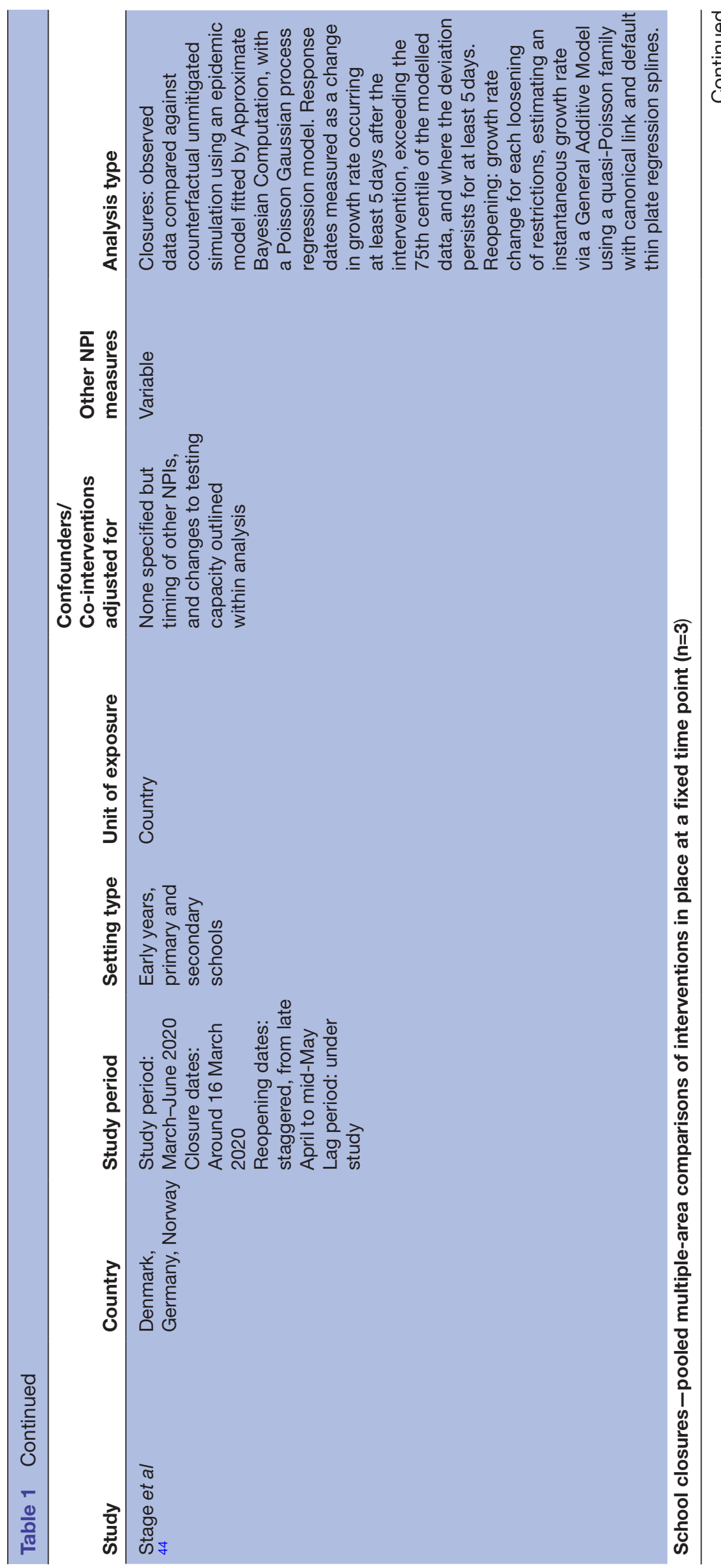


$\frac{\frac{1}{0}}{\frac{0}{\frac{0}{\frac{1}{\pi}}}}$

$\stackrel{0}{\underline{0}}$

곤

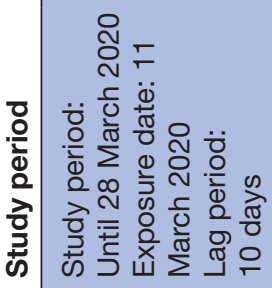



呈 융 융

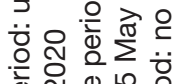

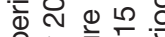

을 文

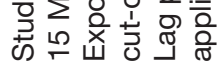
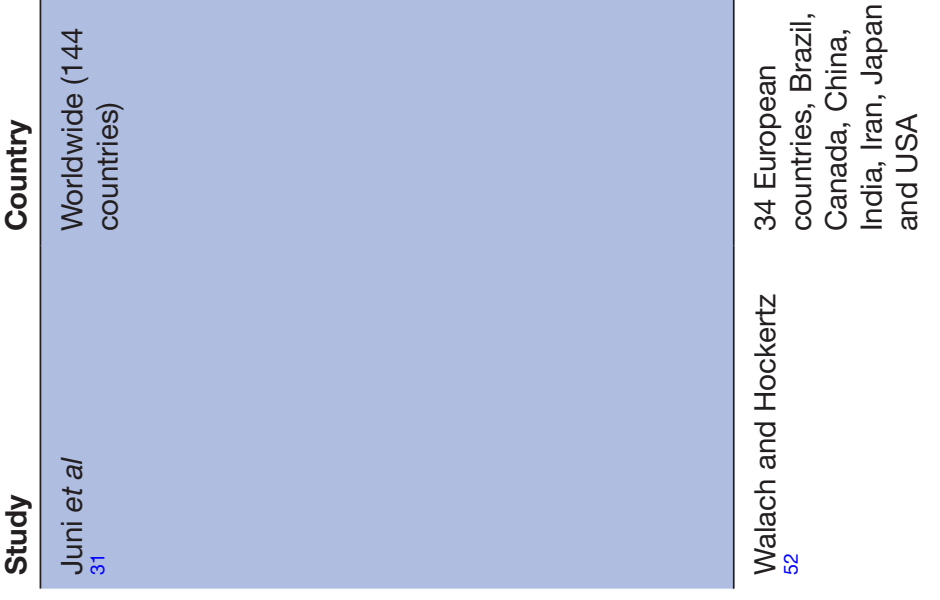


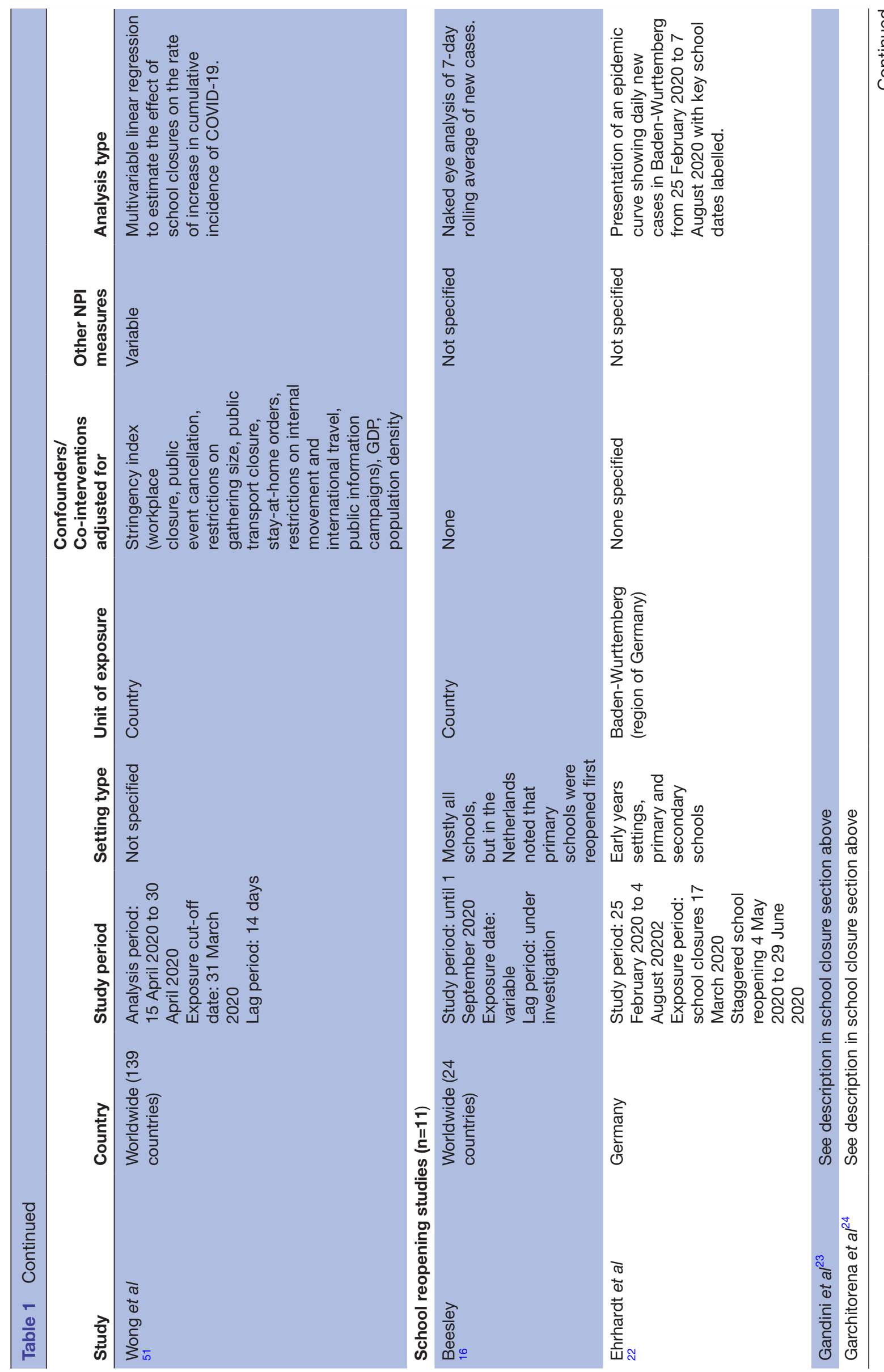




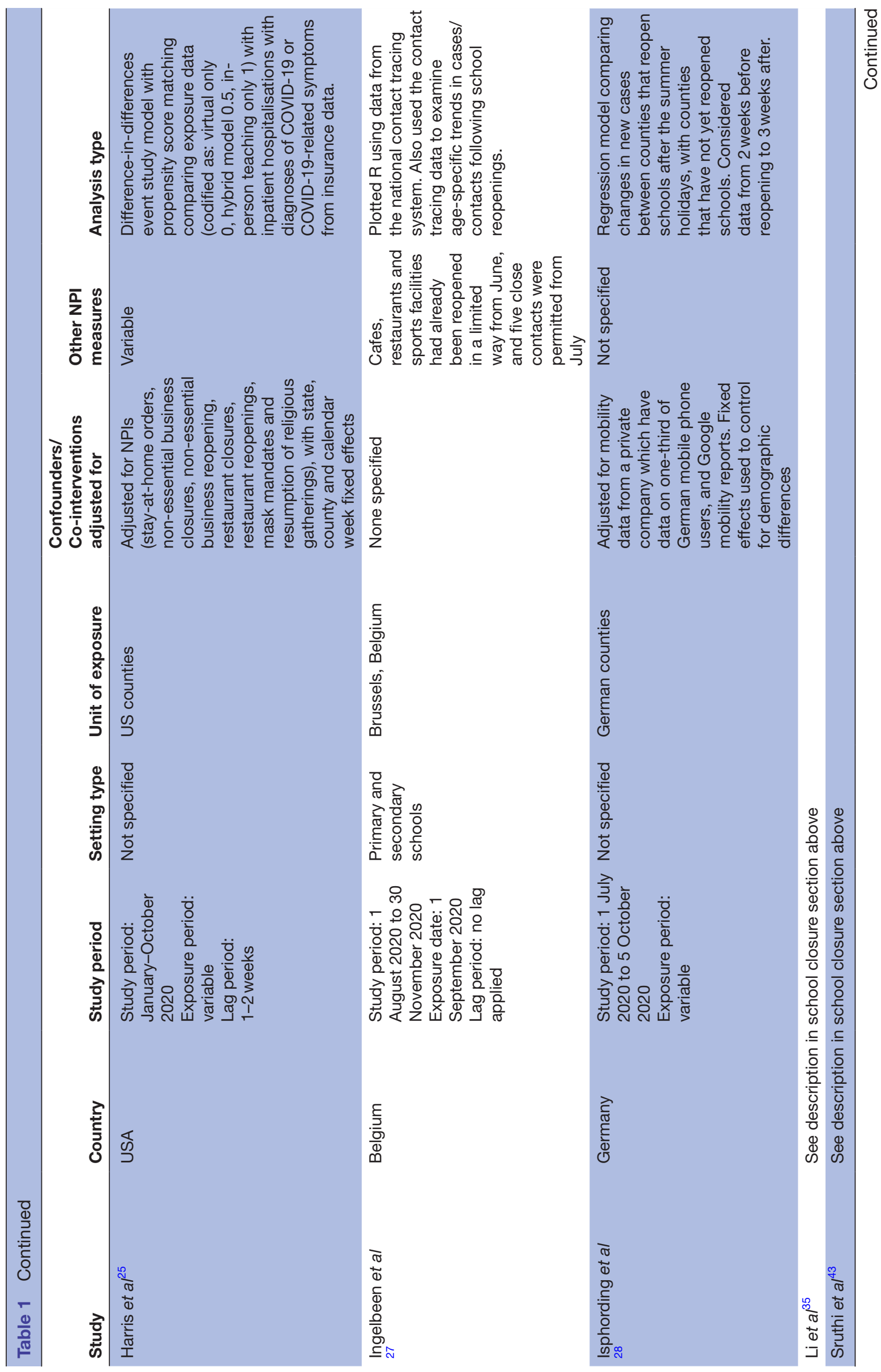




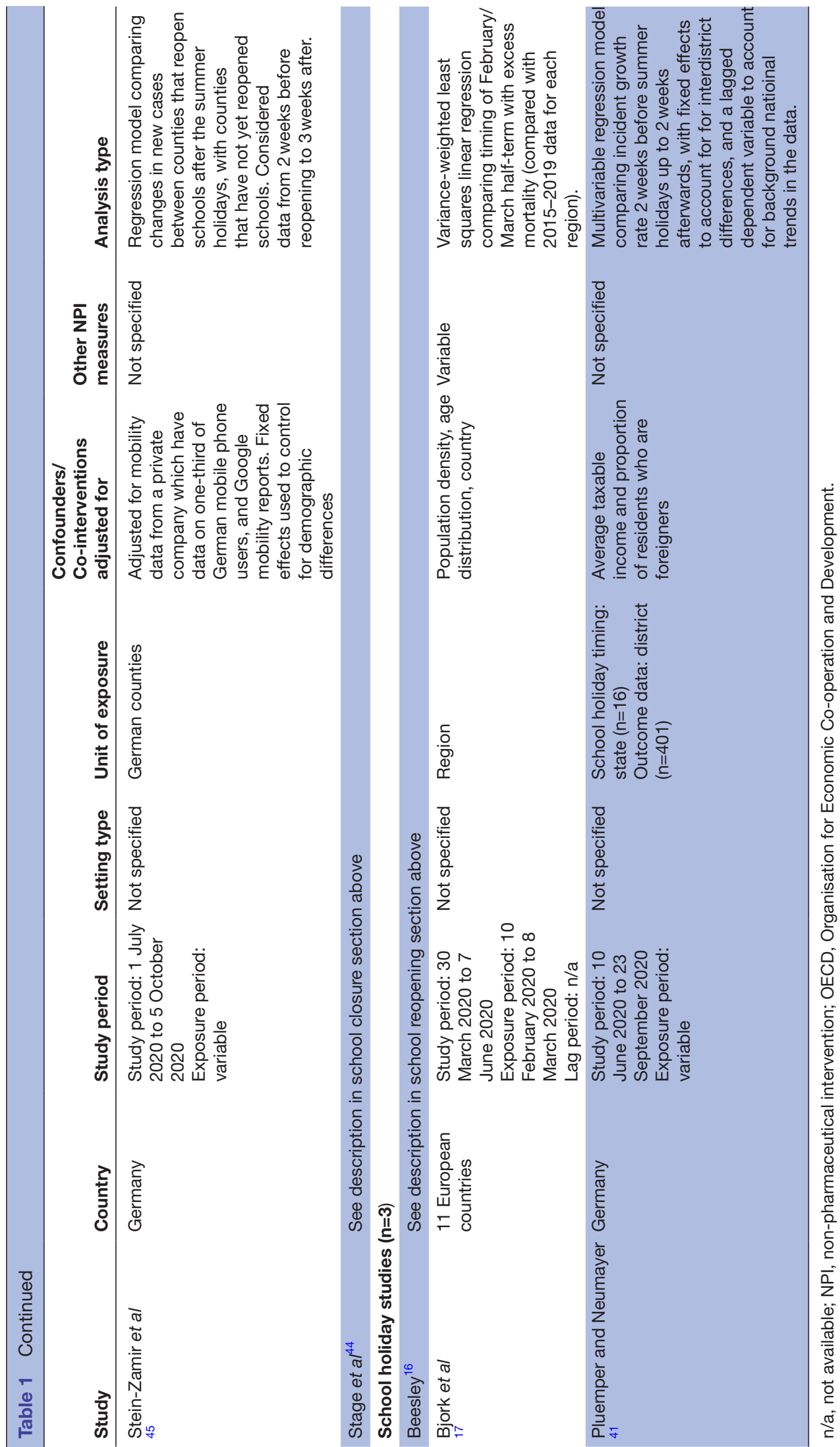




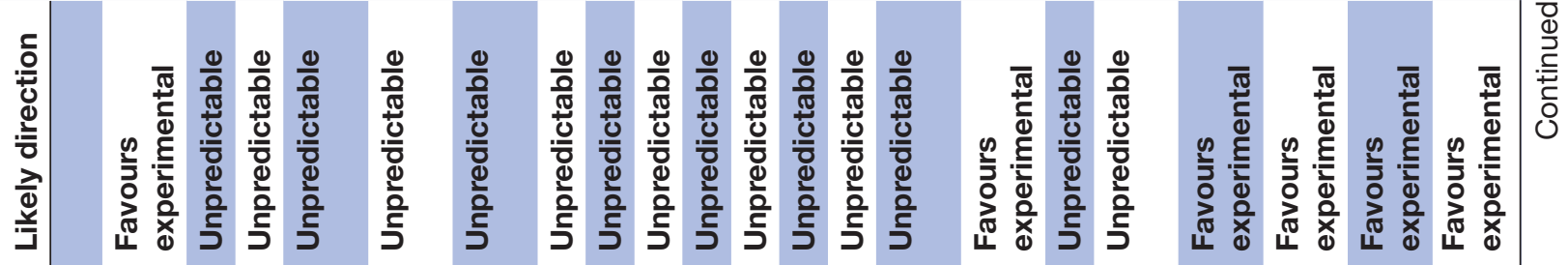

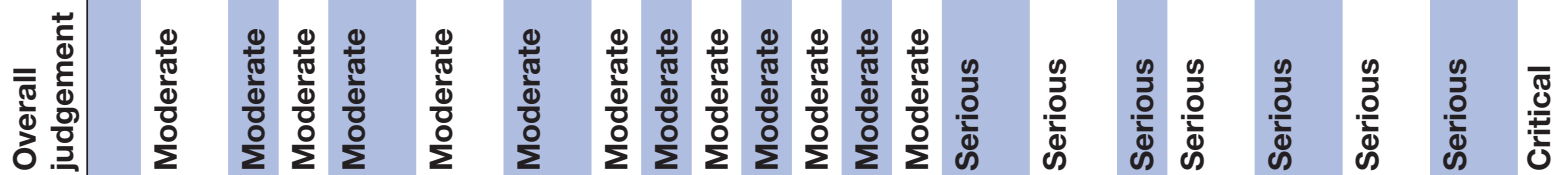

\section{है}

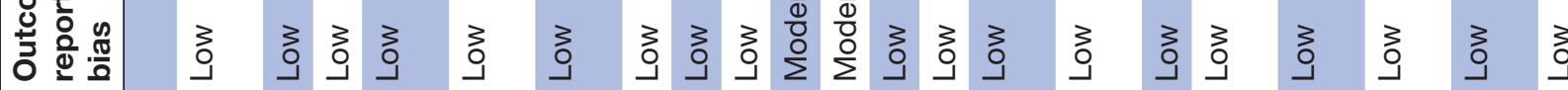

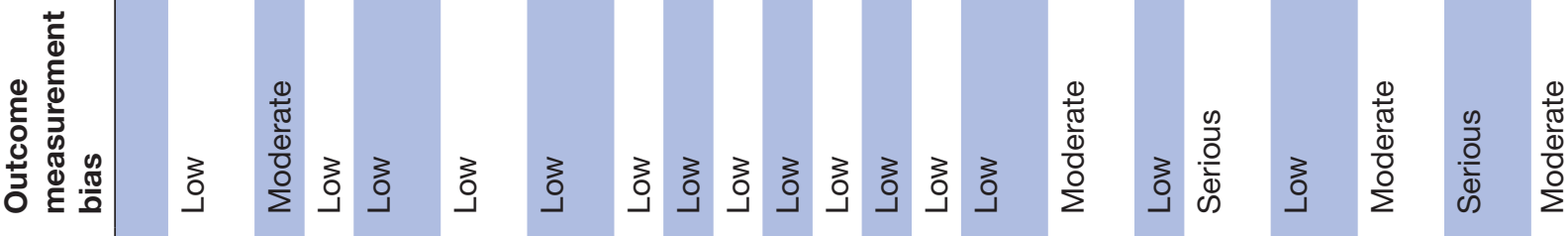

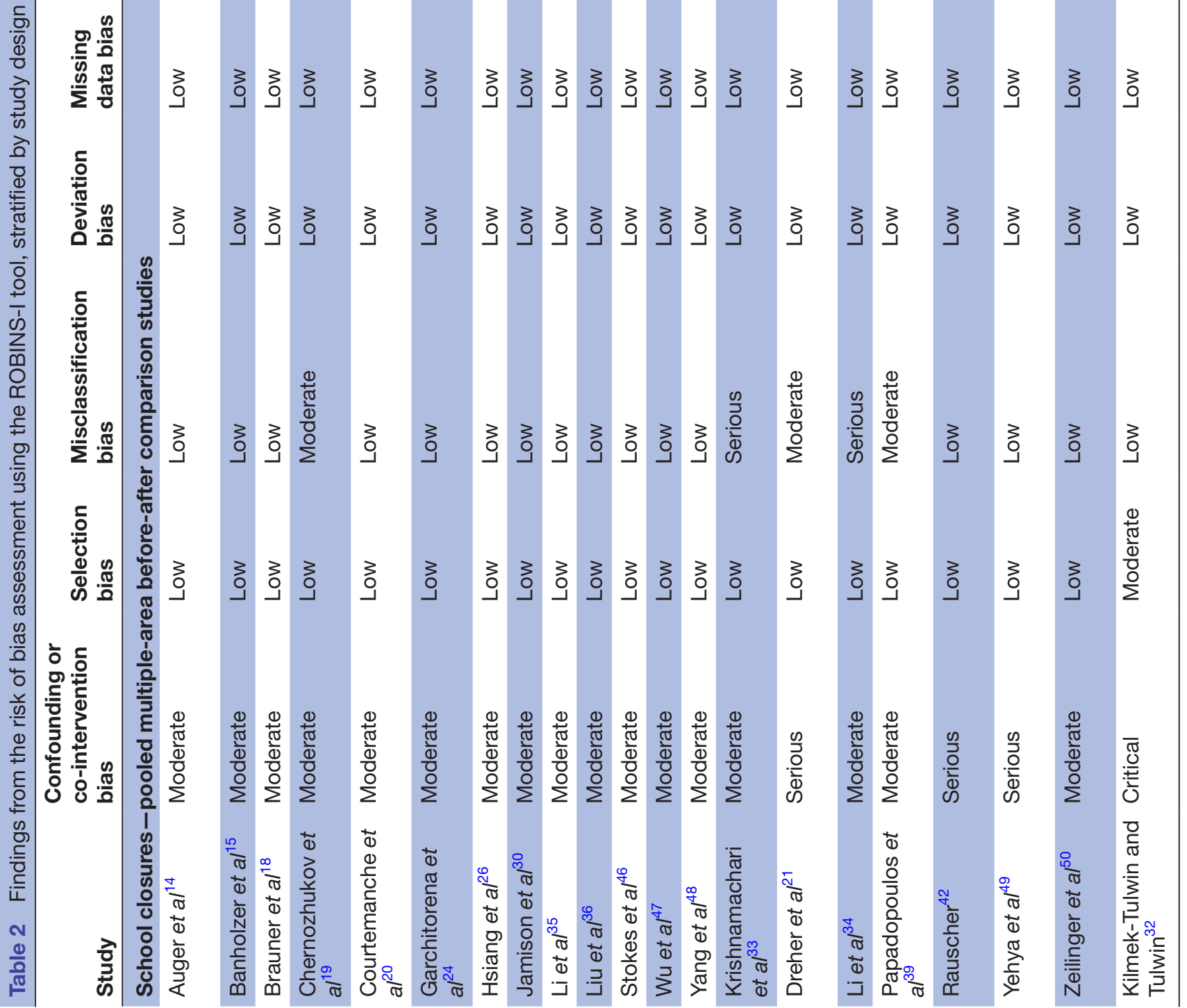




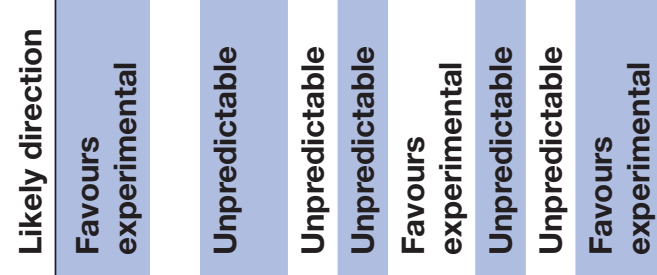

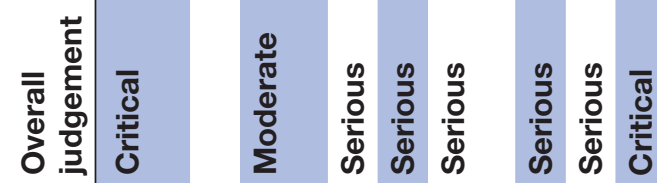

In

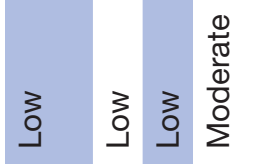

$\frac{15}{2}$

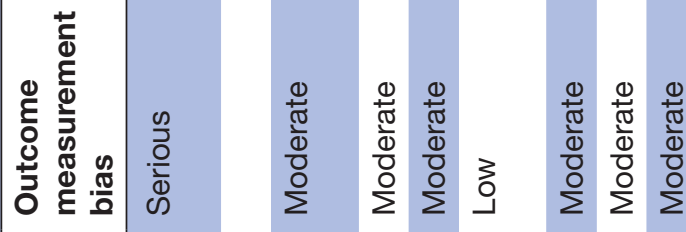

을

象

ㅎำ

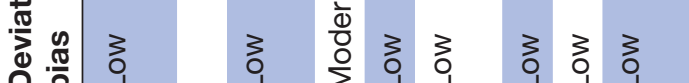

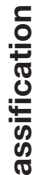

类

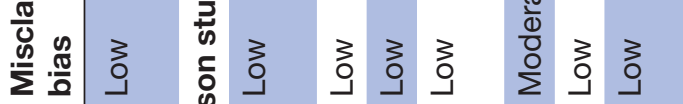

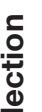

旁

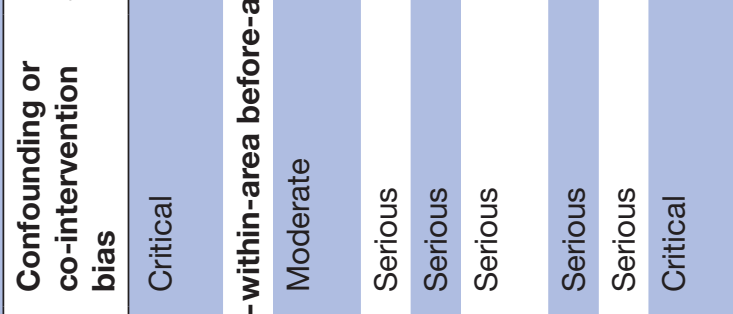

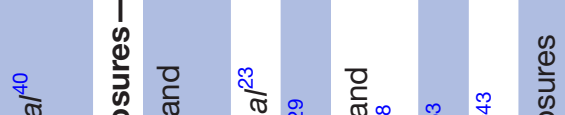

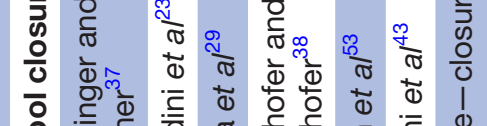

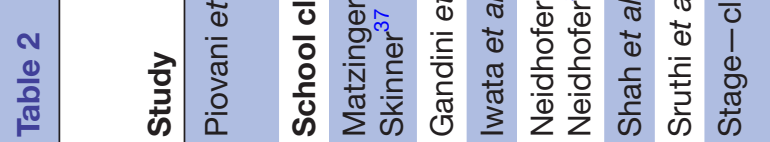

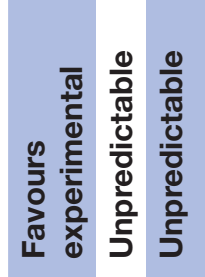

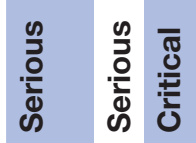

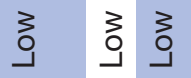

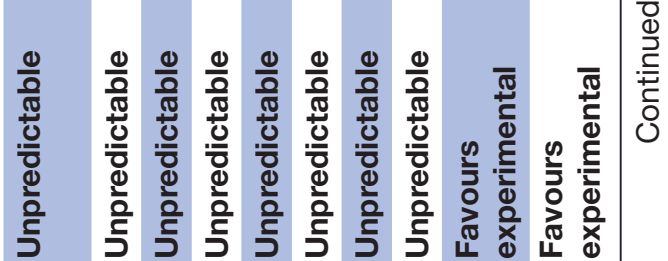

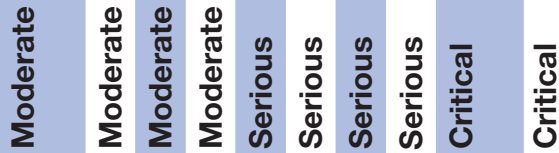

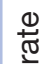

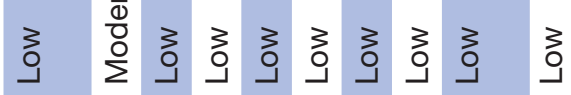

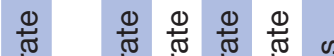

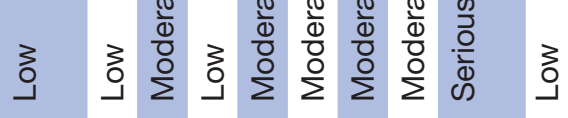<smiles>[CH]1[CH]C=C1</smiles>

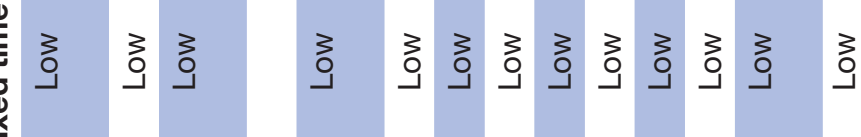

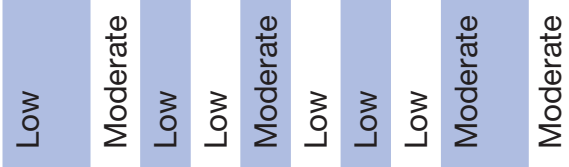

30 3

幽

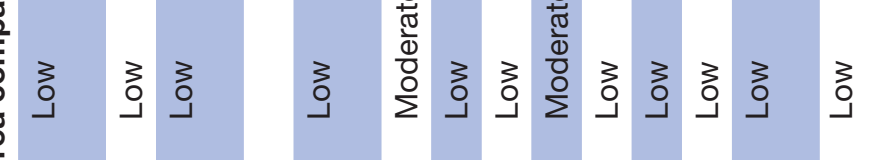

3.

. 迩

$\frac{0}{2}$ 
between school closures and transmission; $5^{1921334653}$ reported mixed findings with evidence of a reduction in transmission in some analyses but not others and 1 study $^{52}$ reported that school closures were associated with an increase in mortality. The reported effect size of closing schools ranged from precise estimates of no effect ${ }^{26}$ to approximately halving the incidence ${ }^{14}$; and from approximately doubling mortality ${ }^{52}$ to approximately halving mortality. ${ }^{14}$ The studies at the highest risk of bias generally reported large reductions in transmission associated with school closures, while studies at lower levels of bias reported more variable findings (figure 2). Of the school reopening studies, $\operatorname{six}^{22-25} 2844$ reported no increase in transmission associated with reopening of schools, while two ${ }^{1643}$ reported mixed findings and three ${ }^{273545}$ reported increases in transmission. Of the four school reopening studies at lowest risk of bias, ${ }^{24252835}$ three $^{242528}$ reported no association between school reopenings and transmission.

\section{Narrative synthesis of findings}

School closures

Pooled multiple-area before-after comparisons


analysed before-after data on multiple geographical units, and then pooled the results into one unified estimate of effect (generally by using regression analysis). These studies relied on different timings of NPI implementation in different areas to establish their independent effects, and were therefore at risk of collinearity if compared areas implemented the same NPIs at similar times. These studies were also at risk of bias from sociocultural differences between compared areas.

Of these studies, $11^{14243234-36404248-50}$ reported that school closures were associated with significantly reduced community transmission of SARS-CoV-2, $7^{15} 182026303947$ reported no association and $4^{19213346}$ reported mixed findings. Those studies found to be at higher risk of bias, generally because they were judged not to have adjusted appropriately for NPIs, testing or sociodemographic data, tended to report reductions in transmission; whereas those studies at lower risk of bias were as likely to report null effects as they were reductions (see figure 2).

Of the three studies ${ }^{20}$ using this approach which were considered to be at the lowest risk of confounding, two reported no association and one reported that school closures reduced transmission. Courtemanche et $a l^{20}$ used a fixed effects model (to account for interarea sociodemographic differences) in an event study design to estimate the effect of NPIs (including school closures) on SARS-CoV-2 incidence in US counties between March and April 2020. They adjusted for relevant NPIs, testing regime confounders and underlying trends in each counties' growth rates, and reported a null effect of school closures on growth rate, applying a lag of either 10 or 20 days. Hsiang et $a l^{26}$ used a reduced form of econometric regression to compare changes in incidence in French regions, Italian regions and US states (in three 


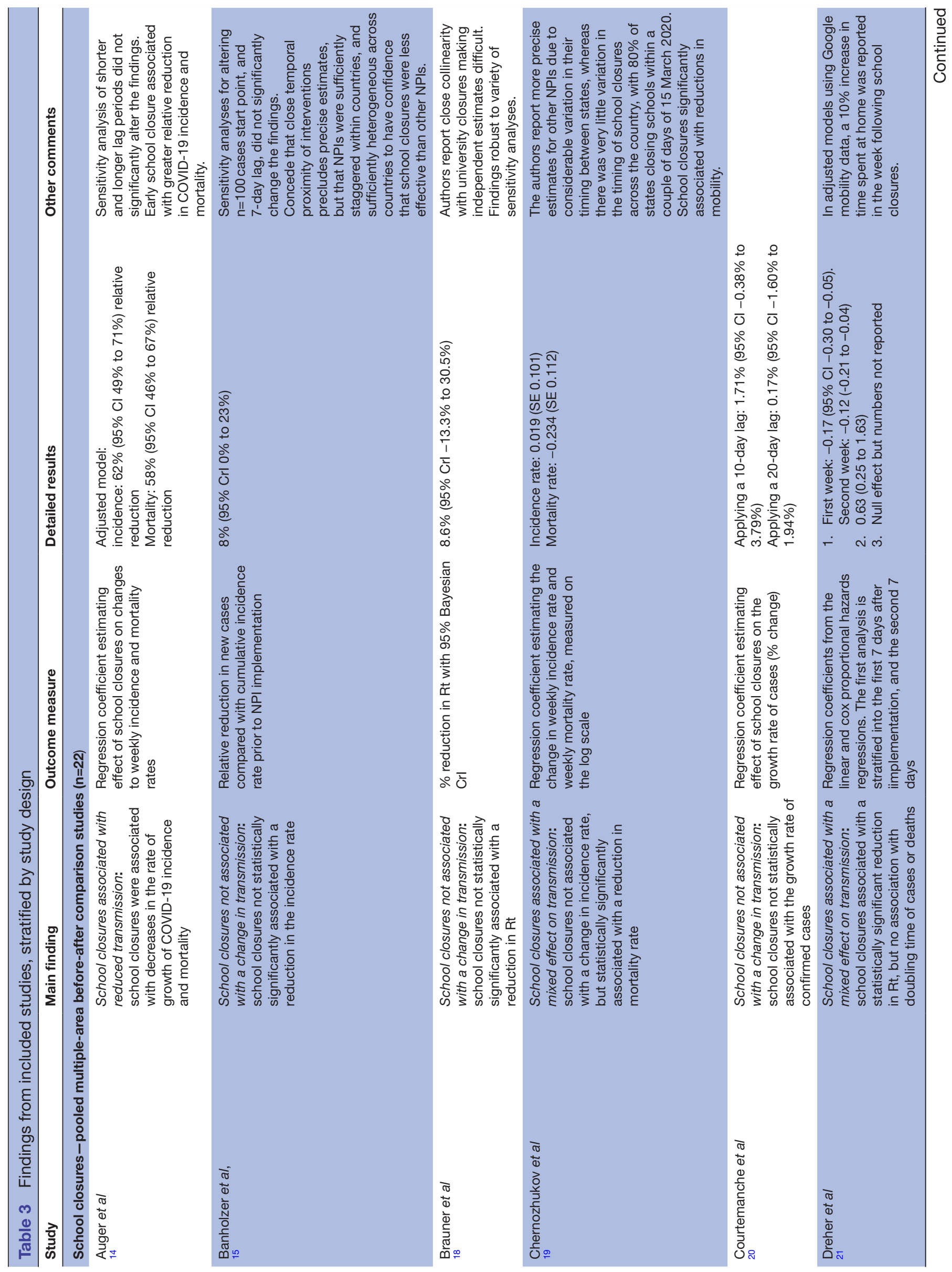




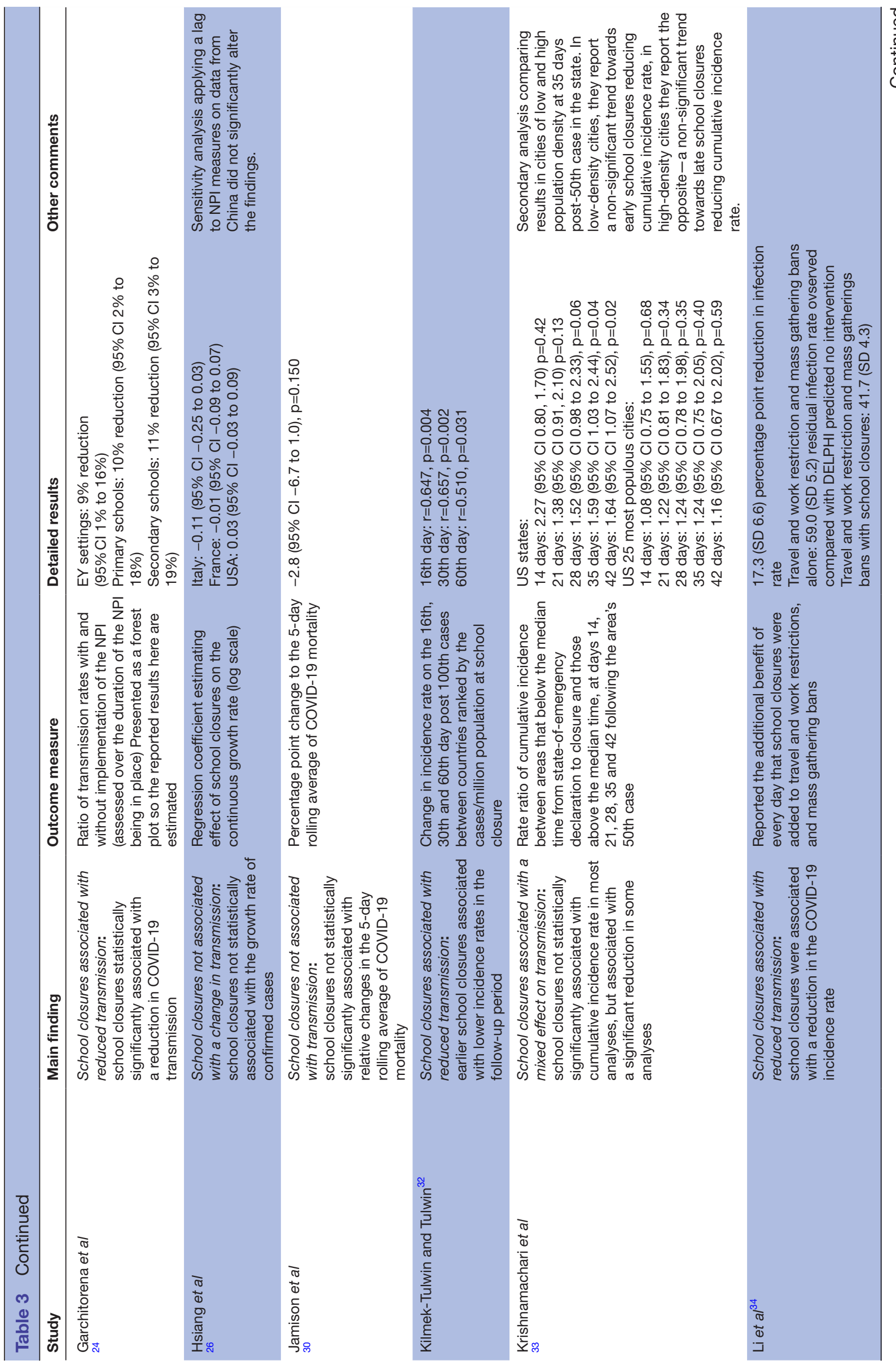









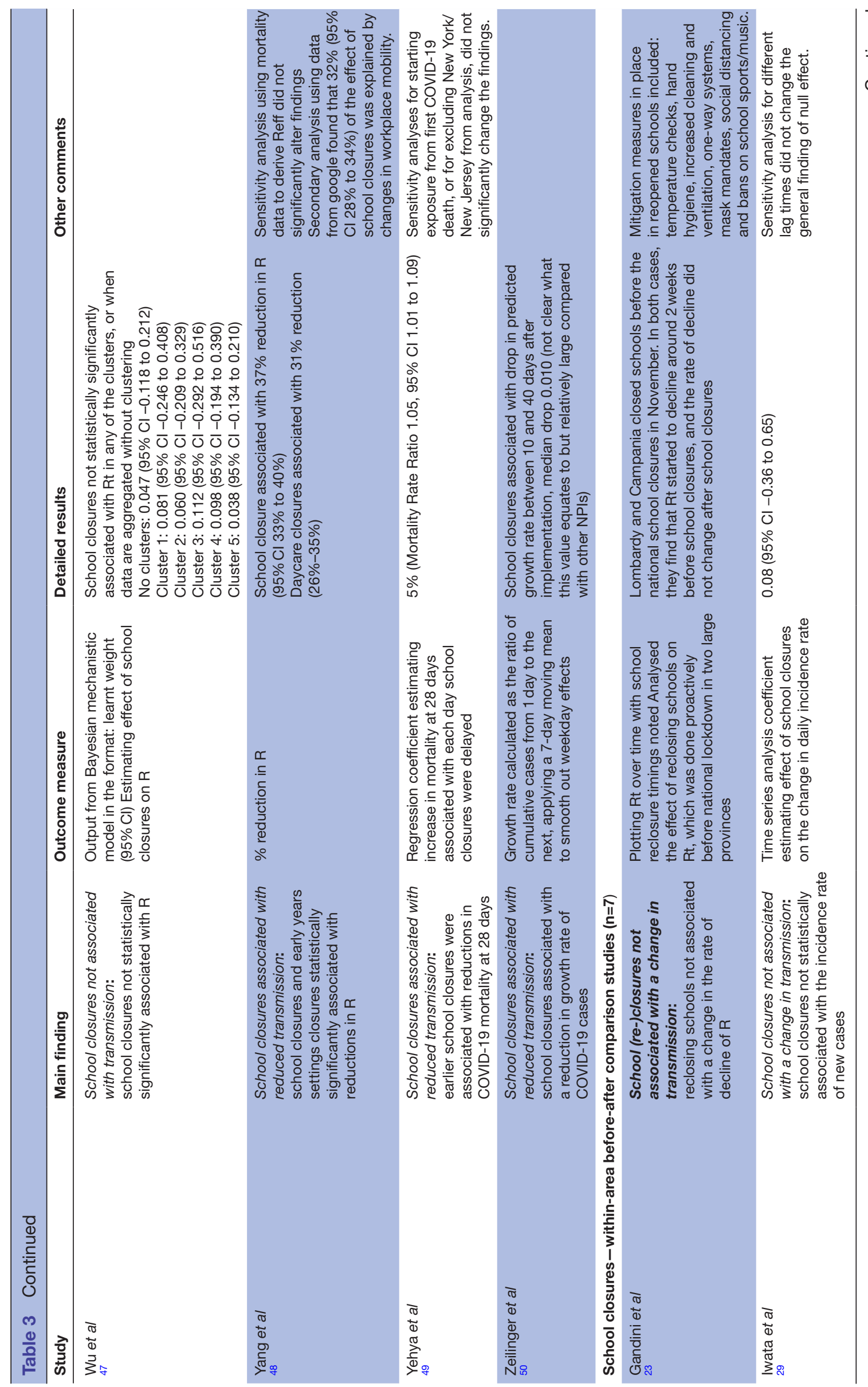


Open access

a

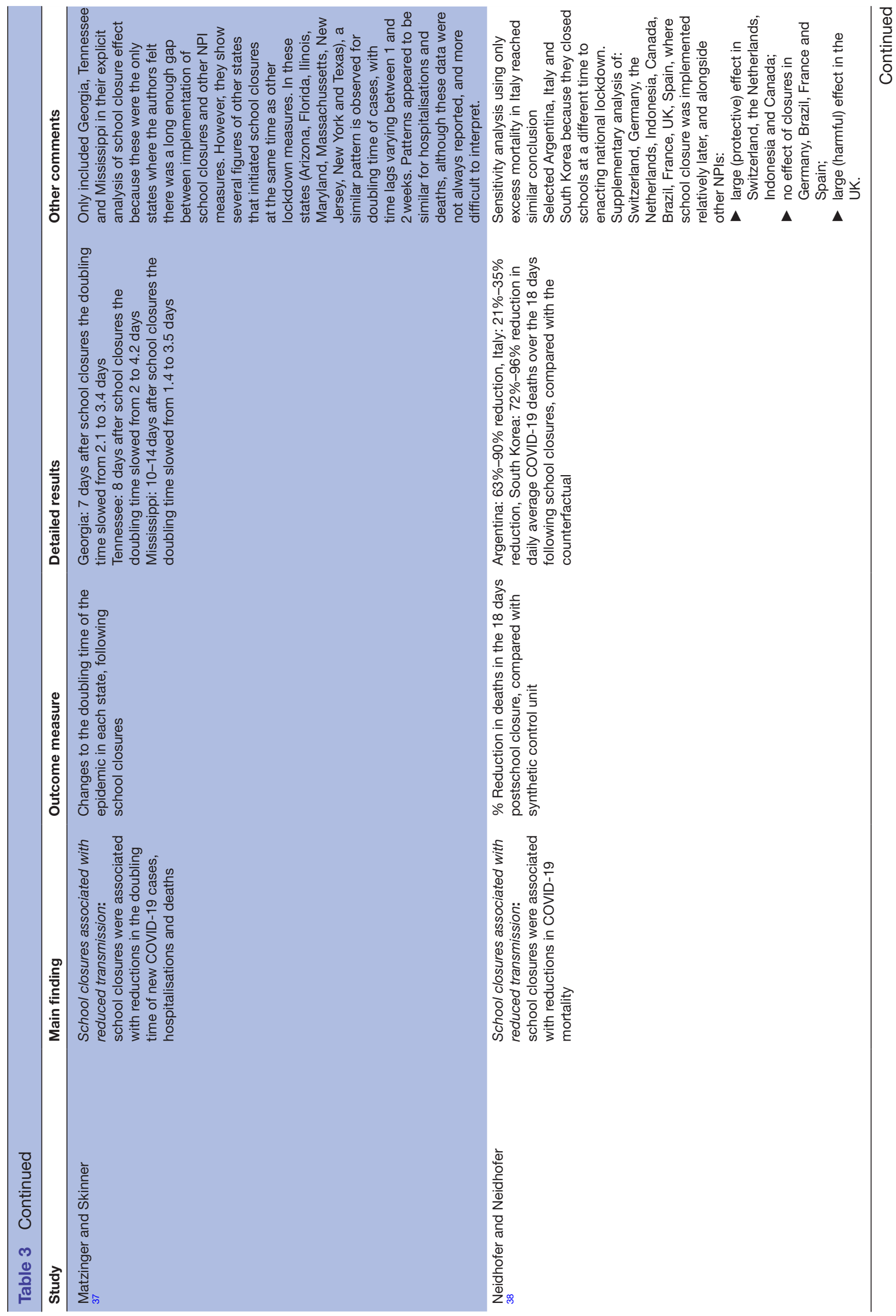

28

Walsh S, et al. BMJ Open 2021;11:e053371. doi:10.1136/bmjopen-2021-053371 


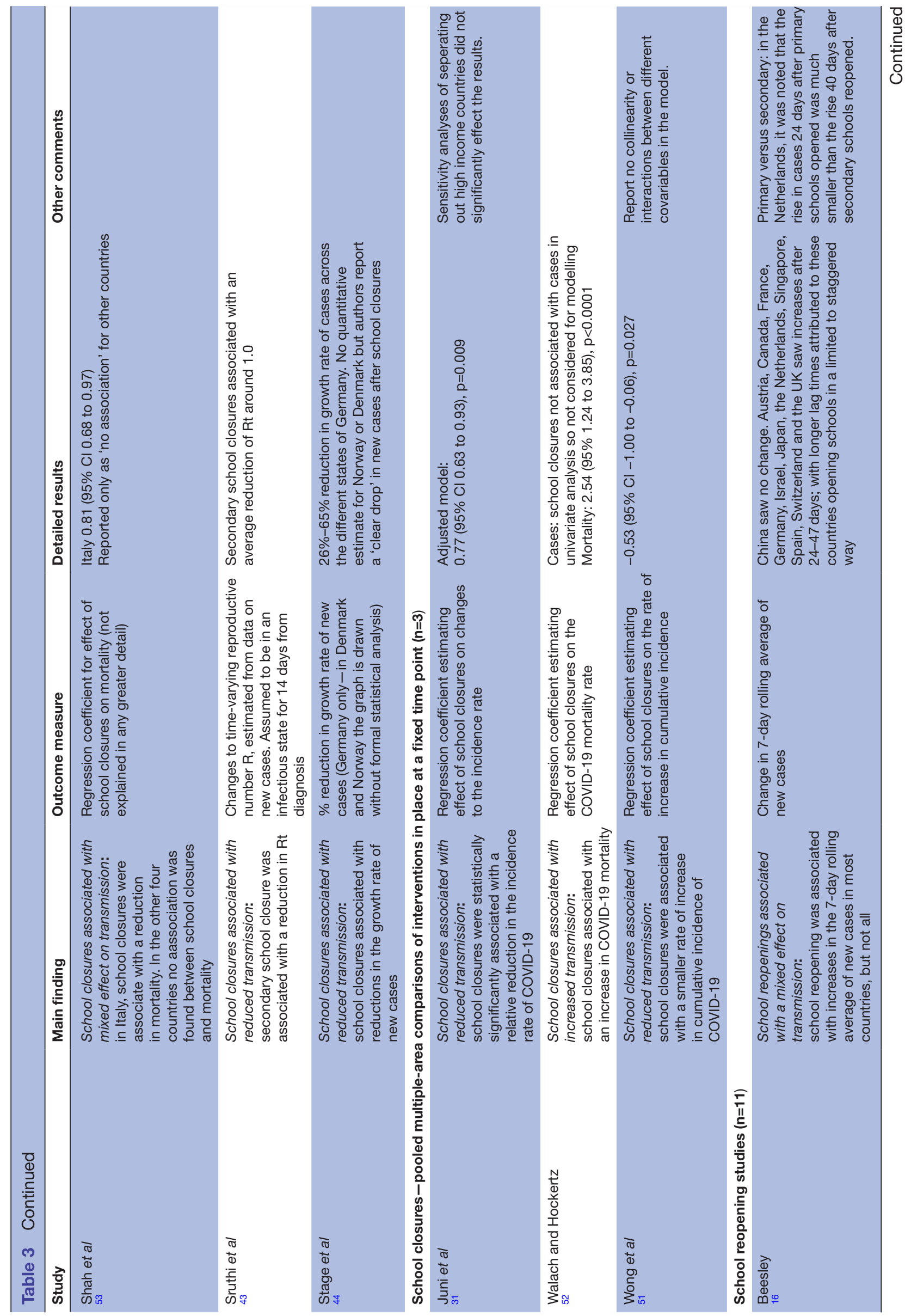




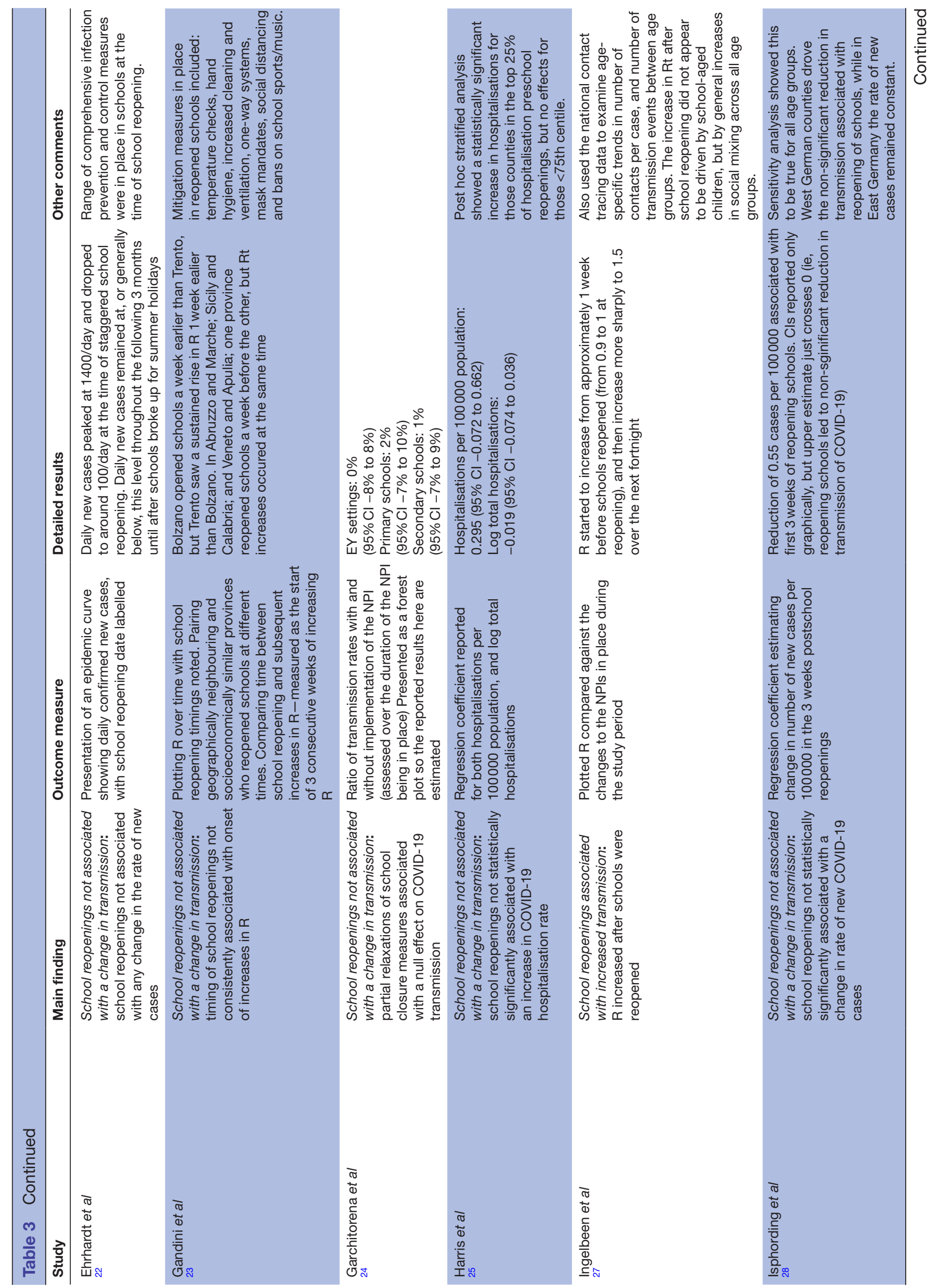




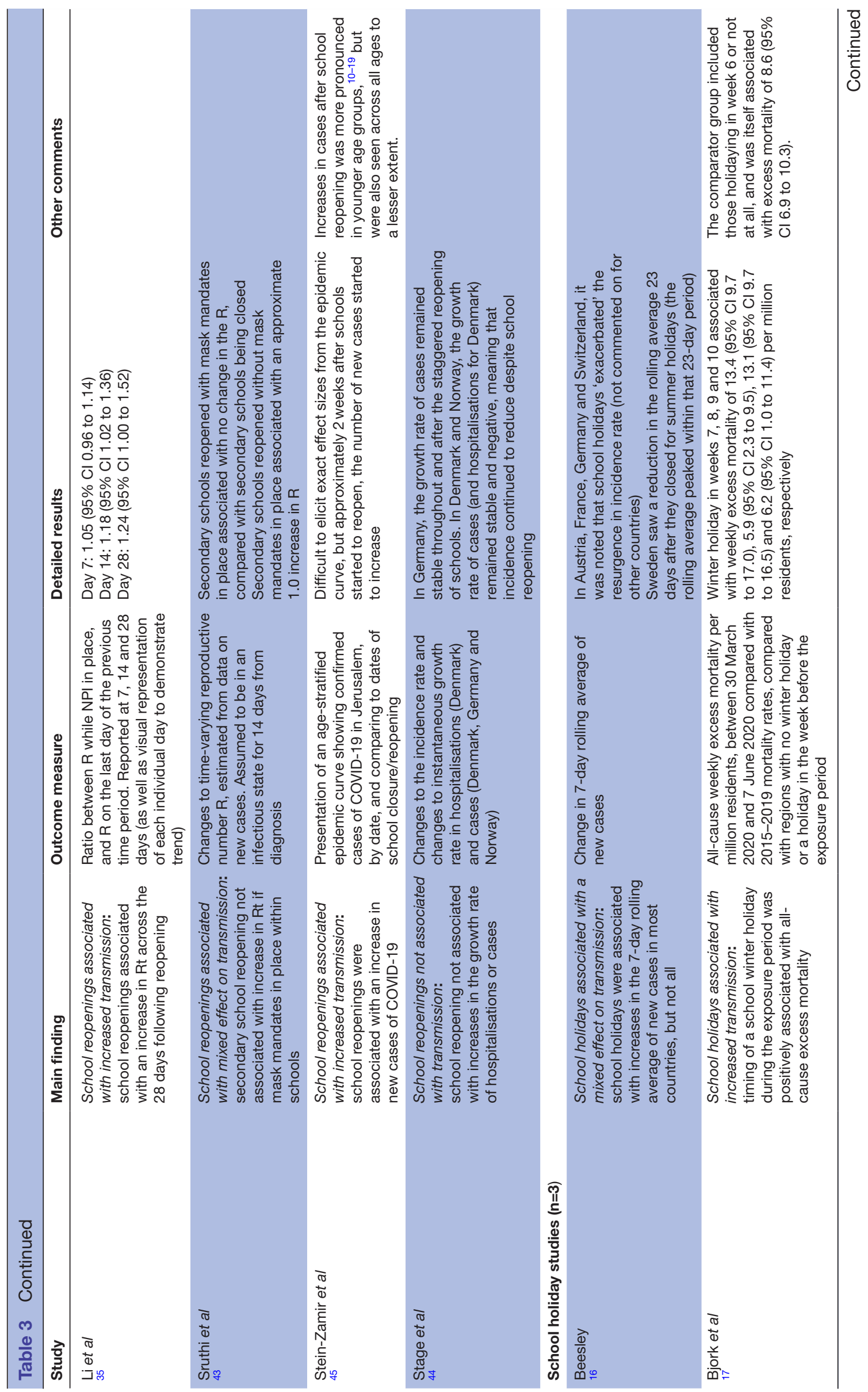



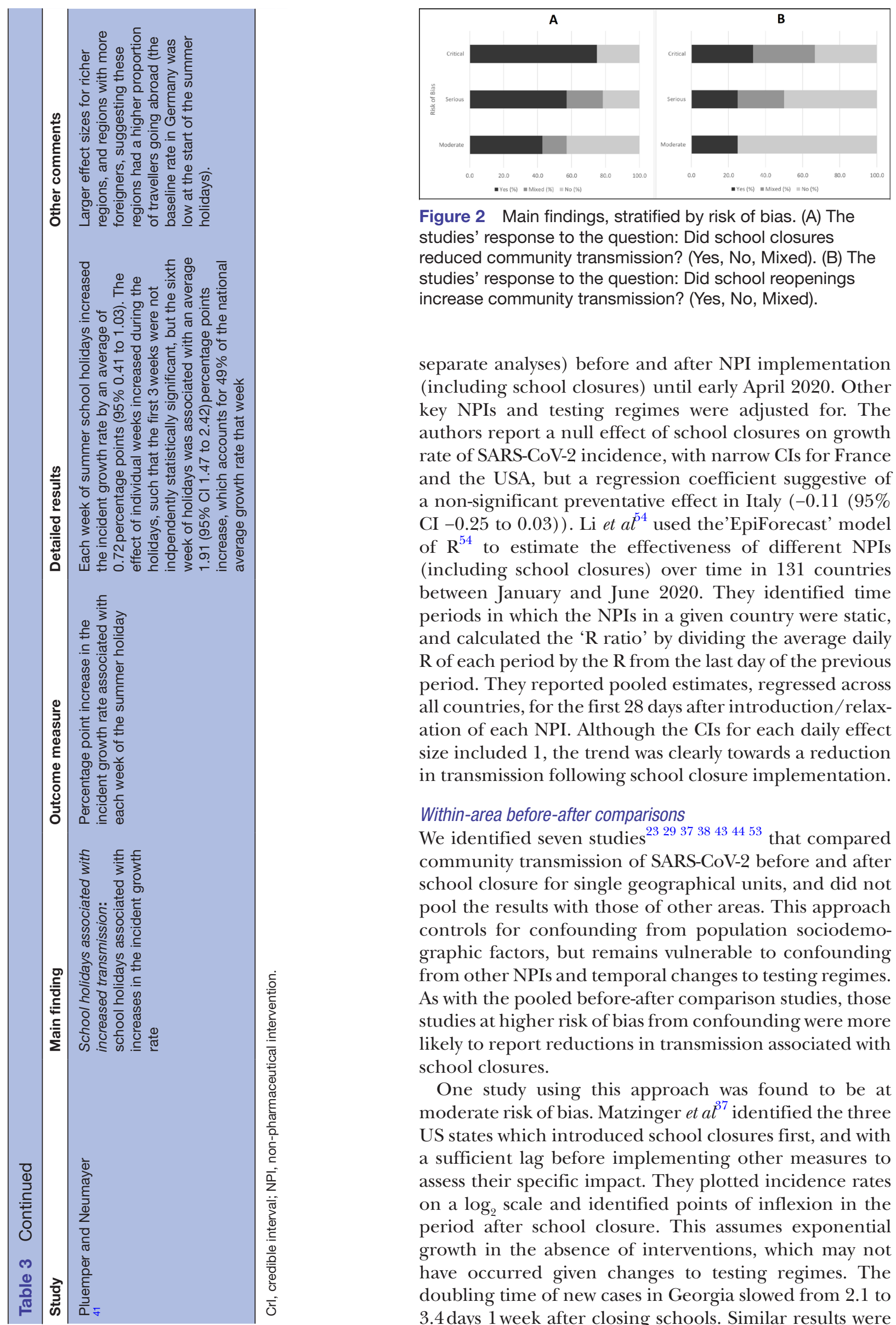

Figure 2 Main findings, stratified by risk of bias. (A) The studies' response to the question: Did school closures reduced community transmission? (Yes, No, Mixed). (B) The studies' response to the question: Did school reopenings increase community transmission? (Yes, No, Mixed).

separate analyses) before and after NPI implementation (including school closures) until early April 2020. Other key NPIs and testing regimes were adjusted for. The authors report a null effect of school closures on growth rate of SARS-CoV-2 incidence, with narrow CIs for France and the USA, but a regression coefficient suggestive of a non-significant preventative effect in Italy $(-0.11(95 \%$ CI -0.25 to 0.03$)$ ). Li et a $\tilde{l}^{54}$ used the'EpiForecast' model of $\mathrm{R}^{54}$ to estimate the effectiveness of different NPIs (including school closures) over time in 131 countries between January and June 2020. They identified time periods in which the NPIs in a given country were static, and calculated the ' $\mathrm{R}$ ratio' by dividing the average daily $\mathrm{R}$ of each period by the $\mathrm{R}$ from the last day of the previous period. They reported pooled estimates, regressed across all countries, for the first 28 days after introduction/relaxation of each NPI. Although the CIs for each daily effect size included 1 , the trend was clearly towards a reduction in transmission following school closure implementation.

\section{Within-area before-after comparisons}

We identified seven studies 23293738434453 that compared community transmission of SARS-CoV-2 before and after school closure for single geographical units, and did not pool the results with those of other areas. This approach controls for confounding from population sociodemographic factors, but remains vulnerable to confounding from other NPIs and temporal changes to testing regimes. As with the pooled before-after comparison studies, those studies at higher risk of bias from confounding were more likely to report reductions in transmission associated with school closures.

One study using this approach was found to be at moderate risk of bias. Matzinger $e t a b^{37}$ identified the three US states which introduced school closures first, and with a sufficient lag before implementing other measures to assess their specific impact. They plotted incidence rates on a $\log _{2}$ scale and identified points of inflexion in the period after school closure. This assumes exponential growth in the absence of interventions, which may not have occurred given changes to testing regimes. The doubling time of new cases in Georgia slowed from 2.1 to 3.4 days 1 week after closing schools. Similar results were 
observed in Tennessee (2.0 to 4.2 days after 1 week) and Mississippi (1.4 to 3.4 days after 2 weeks). The authors also noted inflexion points for hospitalisations and mortality at later time points, although numerical changes were not reported. Tennessee showed a slowing in hospitalisations 1 week after cases, and mortality 1 week after hospitalisation. Mississippi showed a slowing in hospitalisations and mortality at the same time, 1 week after cases-the authors do not comment on this discrepancy. Georgia lacked early hospitalisation data to make such a comparison.

\section{Pooled multiple-area comparisons of interventions in place at a fixed time point}

Three studies ${ }^{31} 5152$ considered countries from around the world using a design in which NPIs were considered as binary variables on a specific date (ie, in place or not in place), and the cumulative incidence or mortality to that point was compared with the number of new cases of COVID-19 over a subsequent follow-up period; countries were then compared using regression analysis to elicit independent effect sizes for individual policies including school closures. This approach reduces bias from different testing regimes over time and between countries. However, the use of a single cut-off date for whether school closure was in place means that the effects of long-standing and recent school closures were pooled, introducing misclassification bias. Two of these studies $^{3151}$ were at serious risk of bias and reported that school closures were associated with lower incidence; and one study ${ }^{52}$ was at critical risk of bias and reported that closing schools was not associated with incidence but was associated with increased mortality. Each of these studies was at high risk of confounding from other NPIs, in addition to the risk of misclassification bias described above.

\section{School reopening studies}

Eleven studies ${ }^{16}$ 22-25 $27283543-45$ considered the effect of school reopening on subsequent SARS-CoV-2 community transmission. ${ }^{24}$ Of these, five were pooled multiplearea before-after comparison studies, ${ }^{24} 25283543$ and six were within-area multiple-area before-after comparison studies. 162223274445 These studies benefited from more staggered lifting of restrictions (compared with their implementation), and more stable testing regimes.

Of the four studies at a lower risk of bias, ${ }^{24} 252835$ three 242528 reported that schools were reopened without associated increases in transmission, while one ${ }^{35}$ reported increased transmission. Garchitorena et $a l^{24}$ compared incidence data, with adjustment for underdetection, from 32 European countries, using multivariate linear regression models with adjustment for other NPIs and fixed effects to account for intercountry sociodemographic differences. They reported no association with incidence rates up to 16 September 2020 of reopening early years settings $(0 \%$ mean change in incidence rate $(95 \% \mathrm{CI}$ $-8 \%$ to $8 \%)$ ), primary schools $(2 \%(95 \%$ CI $-7 \%$ to $10 \%)$ ), or secondary schools $(-1 \%$ (95\% CI $-7 \%$ to $9 \%))$. Harris $e t a l^{25}$ estimated the effect of school reopenings on
COVID-19 hospitalisation in the USA using an event study model, with analysis at the county-level. They adjusted for other NPIs, and used fixed effects to account for calendar week effects and intercounty differences. They applied a 1-week lag period, and compared data from 10 weeks before to 6 weeks after school reopenings. They initially report null effects when pooling the effects across all counties, however, post hoc sensitivity analyses suggested that there were increases in hospitalisations for counties that were in the top $25 \%$ of baseline hospitalisation rate at school reopening (compared with null effects for the bottom $75 \%$ ). Isphording et $a l^{28}$ compared changes to the COVID-19 incidence rate in German counties that were first to reopen schools after the summer holidays, with those yet to reopen (noting that the timing of such decisions was set years in advance, and not changed due to the pandemic). They considered data from 2 weeks before to 3 weeks after school reopenings, and adjusted for mobility data, and used fixed effects to account for intercounty sociodemographic differences. They reported no association between school reopenings and incidence. One study Li $e t a l,{ }^{35}$ is described above as it reports on the effect of both school closures and school reopenings around the world. As for school closures, their effect sizes for each individual day in the 28-day period postschool reopenings were not always statistically significant, but the data trend is clearly that of an increase in transmission associated with school reopenings.

The seven studies ${ }^{1622232743-45}$ at serious and critical risk of confounding are more difficult to interpret, again predominantly due to the high risk of confounding. Three $^{162344}$ reported no association between school reopening and transmission, two ${ }^{22} 43$ reported mixed findings and $\mathrm{two}^{27} 45$ reported increased transmission following reopening of schools.

\section{School holiday studies}

Three studies ${ }^{16} 17^{41}$ reported changes in SARS-CoV-2 community transmission associated with school holidays. These holidays occurred according to predetermined timetables and are therefore unlikely to be influenced by background trends in infections. Two studies examined associations between timing of summer holidays on incidence rates in Germany ${ }^{41}$ and in multiple European countries, ${ }^{16}$ respectively. The other study ${ }^{17}$ reported on the timing of the February/March 2020 half-term break timing in countries that neighbour the Alps. Of these, one reported mixed findings on the effect of summer holidays, ${ }^{16}$ and two reported that school holidays were associated with increased transmission. ${ }^{17}{ }^{41}$ The authors of these studies considered the primary exposure to be increased social contact from international travel, rather than decreases from the temporary closure or schools.

\section{Different school setting types}

One school closure study, ${ }^{48}$ three school reopening studies $^{162244}$ and one study looking at closures and 
reopenings ${ }^{24}$ considered evidence of independent effects for different types of school closures.

Two studies reported independent effect sizes for different settings, but found considerable overlap between the effect sizes, and noted high temporal correlation between the policy timings meaning that collinearity limits the interpretability of the findings. Garchitorena $e t$ $a l^{24}$ (moderate risk of bias) reported the effect of both school closures and school reopenings on changes to $\mathrm{R}$ in 32 European countries, with almost completely overlapping estimates of transmission reductions associated with closures in early years settings, primary schools and secondary schools; and equally null effects for each setting associated with reopenings. Yang et $\mathrm{t}^{48}$ (moderate risk of bias) reported that school closures in US counties (presumed primary and secondary combined) were associated with $37 \%$ (95\% CI $33 \%$ to $40 \%$ ) reductions in $\mathrm{R}$, compared with $31 \%$ reductions for early years settings (95\% CI $26 \%$ to $35 \%)$.

Two studies reported staggered reopenings of different school settings, generally with younger children students returning first, and a week or two between each reopenings. Both studies found null effects on transmission overall, and therefore did not report any differential effect by setting type. Stage $e t a l^{44}$ (serious risk of bias) noted staggered reopenings in Norway, Denmark and Germany. Ehrhardt et al ${ }^{22}$ (critical risk of bias) noted staggered reopenings of schools in Baden-Wuttemberg (a region of Germany).

Beesley ${ }^{16}$ (critical risk of bias) noted that increases in the 7-day rolling average of new cases were greater in the 40 days after secondary school reopening than they were in the 24 days following primary schools reopening. However, this study is at high risk of confounding from other NPIs, and it is not clear why the chosen (and different) lag periods were applied.

\section{DISCUSSION}

We identified 40 studies that provided a quantitative estimate of the impact of school closures or reopening on community transmission of SARS-CoV-2. The studies included a range of countries and were heterogenous in design. Among higher quality, less confounded studies of school closures, 6 out of 14 reported that school closures had no effect on transmission, 6 reported that school closures were associated with reductions in transmission, and 2 reported mixed findings (figure 2); with findings ranging from no association to a $60 \%$ relative reduction in incidence and mortality rate. ${ }^{14}$ Most studies of school reopening reported that school reopening, with extensive infection prevention and control measures in place and when the community infection levels were low, did not increase community transmission of SARS-CoV-2.

The strength of this study is that it draws on empirical data from actual school closures and reopenings during the COVID-19 pandemic and includes data from 150 countries. By necessity, we include observational rather than randomised controlled studies, as understandably no jurisdictions have undertaken such trials. We were unable to meta-analyse due to study heterogeneity. We were unable to meaningfully examine differences between primary and secondary schools as very few studies distinguished between them, despite the different transmission patterns for younger and older children. Data are also lacking from low-income countries, where sociocultural factors may produce different effects of school closures on transmission to high-income settings, leaving a substantial gap in the evidence base. Data in these studies come exclusively from 2020, and many studies report only up to the summer months, it is therefore unclear whether our findings are robust to the effects of new SARS-CoV-2 variants and vaccines.

A major challenge with estimating the 'independent' effect of school closures, acknowledged by many of the studies, is disentangling their effect from other NPIs occurring at the same time. While most studies tried to account for this, it is unclear how effective these methods were. Even where adjustment occurred there is a risk of residual confounding, which likely overestimated preventative associations; and collinearity (highly correlated independent variables meaning that is impossible to estimate specific effects for each) which could bias results towards or away from the null. One exception was a paper by Matzinger and Skinner, ${ }^{37}$ which focused on three US states that implemented school closures first and without co-interventions, and reported a twofold increase in the time for cases to double 1 week after school closures. However, it is possible that the benefits observed here may be attributable, at least in part, to a 'signalling effect' with other changes to social mobility (eg, working from home) being prompted by school closures. Another approach, although ineligible for inclusion in our study, is to examine transmission data for breakpoints, and then work backwards to see what NPIs were in place at the time. Two studies that did this found that transmission started to drop following other NPIs, before school closures were implemented, and found no change in the gradient of decline after school closures in Switzerland ${ }^{55}$ and Germany. ${ }^{56}$ This may suggest school closures have different effects when implemented first, or on top of other restrictions, perhaps due to a broader signalling effect that the first implemented NPI has on societal mobility patterns. The true independent effect of school closures from the first wave around the world may simply be unknowable.

In contrast, lifting of NPIs in the summer of 2020 (including school reopenings) generally occurred in a more staggered way, and on a background of stable testing regimes and outcome ascertainment. Good-quality observational studies considering data from across 32 European countries ${ }^{24}$ Germany alone ${ }^{28}$ and the $\mathrm{USA}^{25}$ all demonstrated that school reopenings can be successfully implemented without increasing community transmission of SARS-CoV-2, where baseline incidence is low and robust infection prevention and control measures are in place. 
This finding is in keeping with several studies showing little or no effect of school reopening on intraschool transmission rates. ${ }^{6758}$ However, the US-based study did comment that those counties with the highest $25 \%$ of baseline hospitalisations at the time of reopenings (above 40 admissions per 100000 population per week) did see an increase in transmission following school reopenings, although the bottom $75 \%$ of counties did not see any effect. This may explain why the other school reopening study at lower risk of bias ${ }^{35}$ reported a clear, although non-significant, trend towards school reopenings being associated with increases in transmission rates across 131 countries worldwide, with the authors noting "we were unable to account for different precautions regarding school reopening that were adopted by some countries" before citing Israel as an example where an uptick in transmission occurred following reopening, and where 'students were in crowded classrooms and were not instructed to wear face masks'.

The variability in findings from our included studies are likely to reflect issues with study design. However, this may also suggest that there is no single effect of school closures and reopenings on community transmission and that contextual factors modify the impact of closures in different countries and over time. If the purpose of school closures is reduction in social contacts among children, the level of social mixing between children that occurs outside school once schools are closed is likely to be a key determinant of their effect at reducing community transmission. This will be influenced by other NPIs, and other key contextual factors including background prevalence of infection, use of preventive measures in schools prior to closures, age of children affected as well as sociodemographic and cultural factors.

Different countries have adopted different approaches to controlling COVID-19. Early in the pandemic school closures were common, and in some places were one of the first major social distancing measures introduced. The effectiveness of the overall bundle of lockdown measures implemented is proven, but the incremental benefit of school closures remains unclear. In contrast, only one of the four studies of school reopenings assessed at a lower risk of bias reported an increase in community transmission. Collectively, the evidence around school reopenings, while more limited in size, tends to suggest that school reopenings, when implemented during periods of low incidence and accompanied by robust preventive measures, are unlikely to have a measurable impact on community transmission. Further research is needed to validate these findings and their generalisability, including with respect to new variants. These findings are highly important given the harmful effects of school closures. ${ }^{34}$ Policymakers and governments need to take a measured approach before implementing school closures in response to rising infection rates, and look to reopen schools, with appropriate mitigation measures in place, where other lockdown measures have successfully brought community transmission of SARS-CoV-2 under control.

\section{Author affiliations}

${ }^{1}$ Cambridge Public Health, University of Cambridge, Cambridge, UK ${ }^{2}$ MRC Epidemiology Unit, University of Cambridge, Cambridge, UK

${ }^{3}$ Population, Policy \& Practice Department, University College London Institute of Child Health, London, UK

${ }^{4}$ Department of Medicine, University of Cambridge, Cambridge, UK

${ }^{5}$ London School of Hygiene and Tropical Medicine Faculty of Public Health and Policy, London, UK

Twitter Sebastian Walsh @seb_walsh and Jack Michael Birch @jackmbirch Contributors SW, CW, CBo, RMV and OTM designed the review protocol. SW, $\mathrm{AC}, \mathrm{VB}, \mathrm{SR}$ and JMB screened articles for inclusion, assessed risk of bias and performed data extraction. SW and OTM drafted the manuscript. All authors commented on the final manuscript.

Funding The authors have not declared a specific grant for this research from any funding agency in the public, commercial or not-for-profit sectors.

Competing interests None declared.

Patient consent for publication Not required.

Provenance and peer review Not commissioned; externally peer reviewed.

Data availability statement All data relevant to the study are included in the article or uploaded as supplemental information. All included data in this systematic review are already in the public domain.

Supplemental material This content has been supplied by the author(s). It has not been vetted by BMJ Publishing Group Limited (BMJ) and may not have been peer-reviewed. Any opinions or recommendations discussed are solely those of the author(s) and are not endorsed by BMJ. BMJ disclaims all liability and responsibility arising from any reliance placed on the content. Where the content includes any translated material, BMJ does not warrant the accuracy and reliability of the translations (including but not limited to local regulations, clinical guidelines, terminology, drug names and drug dosages), and is not responsible for any error and/or omissions arising from translation and adaptation or otherwise.

Open access This is an open access article distributed in accordance with the Creative Commons Attribution Non Commercial (CC BY-NC 4.0) license, which permits others to distribute, remix, adapt, build upon this work non-commercially, and license their derivative works on different terms, provided the original work is properly cited, appropriate credit is given, any changes made indicated, and the use is non-commercial. See: http://creativecommons.org/licenses/by-nc/4.0/.

\section{ORCID iDs}

Sebastian Walsh http://orcid.org/0000-0001-8894-5006

Avirup Chowdhury http://orcid.org/0000-0001-9817-0603

Vickie Braithwaite http://orcid.org/0000-0002-3366-2903

Jack Michael Birch http://orcid.org/0000-0001-6292-1647

Chris Bonell http://orcid.org/0000-0002-6253-6498

Russell M Viner http://orcid.org/0000-0003-3047-2247

Oliver T Mytton http://orcid.org/0000-0003-3218-9912

\section{REFERENCES}

1 UNESCO. Global monitring of school closures caused by COVID-19 [Internet]. Education:From disruption to recovery, 2020. Available: https://en.unesco.org/covid19/educationresponse [Accessed 18 Dec 2020].

2 Unicef. Framework for reopening schools, 2020.

3 UNESCO. Adverse consequences of school closures [Internet], 2020. Available: https://en.unesco.org/covid19/educationresponse/ consequences [Accessed 18 Dec 2020].

4 Viner R, Russell S, Saulle R. Impacts of school closures on physical and mental health of children and young people: a systematic review. medRxiv 2021:1;2021.02.10.21251526 http://medrxiv.org/content/ early/2021/02/12/2021.02.10.21251526.abstract

5 ECDC. COVID-19 in children and the role of school settings in COVID-19 transmission. Stockholm, 2020.

6 Ismail SA, Saliba V, Lopez Bernal J, et al. SARS-CoV-2 infection and transmission in educational settings: a prospective, cross-sectional analysis of infection clusters and outbreaks in England. Lancet Infect Dis 2021;21:344-53.

7 Viner RM, Mytton OT, Bonell C, et al. Susceptibility to SARSCoV-2 infection among children and adolescents compared with 
adults: a systematic review and meta-analysis. JAMA Pediatr 2021;175:143-56.

8 Panovska-Griffiths J, Kerr CC, Stuart RM, et al. Determining the optimal strategy for reopening schools, the impact of test and trace interventions, and the risk of occurrence of a second COVID-19 epidemic wave in the UK: a modelling study. Lancet Child Adolesc Health 2020:4:817-27.

9 Chang SL, Harding N, Zachreson C, et al. Modelling transmission and control of the COVID-19 pandemic in Australia. Nat Commun 2020;11:5710.

10 Davies NG, Kucharski AJ, Eggo RM, et al. Effects of nonpharmaceutical interventions on COVID-19 cases, deaths, and demand for hospital services in the UK: a modelling study. Lancet Public Health 2020:5:e375-85.

11 Viner RM, Russell SJ, Croker H, et al. School closure and management practices during coronavirus outbreaks including COVID-19: a rapid systematic review. Lancet Child Adolesc Health 2020;4:397-404.

12 Ouzzani M, Hammady H, Fedorowicz Z, et al. Rayyan-a web and mobile APP for systematic reviews. Syst Rev 2016;5:210.

13 Sterne JA, Hernán MA, Reeves BC, et al. ROBINS-I: a tool for assessing risk of bias in non-randomised studies of interventions. BMJ 2016;355:i4919.

14 Auger KA, Shah SS, Richardson T, et al. Association between statewide school closure and COVID-19 incidence and mortality in the US. JAMA 2020;324:859-70.

15 Banholzer N, van WE, Kratzwald B, et al. Estimating the impact of non-pharmaceutical interventions on documented infections with COVID-19: A cross-country analysis [Internet]., 2020. Available: https://medrxiv.org/cgi/content/short/2020.04.16.20062141

16 Beesley R. The role of school reopening in the spread of COVID-19 [Internet], 2020. Available: https://medrxiv.org/cgi/content/short/ 2020.09.03.20187757

17 Bjork J, Mattisson K, Ahlbom A. Excess mortality across regions of Europe during the first wave of the COVID-19 pandemic - impact of the winter holiday travelling and government responses [Internet]., 2020. Available: https://medrxiv.org/cgi/content/short/2020.11.24. 20237644

18 Brauner JM, Mindermann S, Sharma M, et al. The effectiveness and perceived burden of nonpharmaceutical interventions against COVID-19 transmission: a modelling study with 41 countries [Internet], 2020. Available: https://medrxiv.org/cgi/content/short/ 2020.05.28.20116129

19 Chernozhukov V, Kasahara H, Schrimpf P. Causal impact of masks, policies, behavior on early covid-19 pandemic in the U.S. J Econom 2021;220:23-62.

20 Courtemanche C, Garuccio J, Le A, et al. Strong social distancing measures in the United States reduced the COVID-19 growth rate. Health Aff 2020;39:1237-46.

21 Dreher N, Spiera Z, McAuley FM, et al. Impact of policy interventions and social distancing on SARS-CoV-2 transmission in the United States [Internet]., 2020. Available: https://medrxiv.org/cgi/content/ short/2020.05.01.20088179

22 Ehrhardt J, Ekinci A, Krehl H, et al. Transmission of SARS-CoV-2 in children aged 0 to 19 years in childcare facilities and schools after their reopening in may 2020, Baden-Württemberg, Germany. Eurosurveillance 2020;25.

23 Gandini S, Rainisio M, lannuzzo ML. No evidence of association between schools and SARS-CoV-2 second wave in Italy. [Internet], 2020. Available: https://medrxiv.org/cgi/content/short/2020.12.16. 20248134

24 Garchitorena A, Gruson H, Cazelles B, et al. Quantifying the efficiency of non-pharmaceutical interventions against SARS-COV-2 transmission in Europe [Internet], 2020. Available: https://medrxiv. org/cgi/content/short/2020.08.17.20174821

25 Harris D, Ziedan E, Hassig S. The effects of school Reopenings on COVID-19 hospitalizations, 2021.

26 Hsiang S, Allen D, Annan-Phan S, et al. The effect of large-scale anti-contagion policies on the COVID-19 pandemic. Nature 2020;584:262-7.

27 Ingelbeen B, Peckeu L, Laga M. Reducing contacts to stop SARSCoV-2 transmission during the second pandemic wave in Brussels. Belgium, 2020. https://medrxiv.org/cgi/content/short/2020.12.23. 20248795

28 Isphording I, Lipfert M, Pestel N. School Re-Openings after summer breaks in Germany did not increase SARS-CoV-2 cases, 2020.

29 Iwata K, Doi A, Miyakoshi C. Was school closure effective in mitigating coronavirus disease 2019 (COVID-19)? time series analysis using Bayesian inference. International Journal of Infectious Diseases 2020:99:57-61.
30 Jamison J, Bundy D, Jamison D, et al. Comparing the impact on COVID-19 mortality of self-imposed behavior change and of government regulations across 13 countries [Internet]., 2020. Available: https://medrxiv.org/cgi/content/short/2020.08.02. 20166793

31 Jüni $\mathrm{P}$, Rothenbühler $\mathrm{M}$, Bobos $\mathrm{P}$, et al. Impact of climate and public health interventions on the COVID-19 pandemic: a prospective cohort study. Can Med Assoc J 2020;192:E566-73.

32 Klimek-Tulwin M, Tulwin T. Early school closures can reduce the first-wave of the COVID-19 pandemic development. $Z$ Gesundh Wiss 2020:1-7.

33 Krishnamachari B, Dsida A, Zastrow D, et al. Effects of Government Mandated Social Distancing Measures on Cumulative Incidence of COVID-19 in the United States and its Most Populated Cities [Internet], 2020. Available: https://medrxiv.org/cgi/content/short/ 2020.05.22.20110460

34 ML L, Bouardi HT, Lami OS, et al. Forecasting COVID-19 and Analyzing the Effect of Government Interventions [Internet], 2020. Available: https://medrxiv.org/cgi/content/short/2020.06.23. 20138693

35 Li Y, Campbell H, Kulkarni D, et al. The temporal association of introducing and lifting non-pharmaceutical interventions with the time-varying reproduction number (R) of SARS-CoV-2: a modelling study across 131 countries. Lancet Infect Dis 2021;21:193-202.

36 Liu Y, Morgenstern C, Kelly J, et al. The impact of nonpharmaceutical interventions on SARS-CoV-2 transmission across 130 countries and territories. BMC Med 2021;19:40.

37 Matzinger P, Skinner J. Strong impact of closing schools, closing bars and wearing masks during the Covid-19 pandemic: results from a simple and revealing analysis. medRxiv : the preprint server for health sciences 2020.

38 Neidhofer C, Neidhofer G. The effectiveness of school closures and other pre-lockdown COVID-19 mitigation strategies in Argentina, Italy, and South Korea. ZEW Discussion Paper [Internet]., 2020. Available: https://pesquisa.bvsalud.org/portal/resource/en/mdl-20203403367

39 Papadopoulos DI, Donkov I, Charitopoulos K, et al. The impact of lockdown measures on COVID-19: a worldwide comparison [Internet], 2020. Available: https://medrxiv.org/cgi/content/short/ 2020.05.22.20106476

40 Piovani D, Christodoulou MN, Hadjidemetriou A, et al. Effect of early application of social distancing interventions on COVID-19 mortality over the first pandemic wave: an analysis of longitudinal data from 37 countries. J Infect 2021;82:133-42.

41 Pluemper T, Neumayer E. Summer School Holidays and the Growth Rate in Sars-CoV-2 Infections Across German Districts [Internet]., 2020. Available: https://medrxiv.org/cgi/content/short/2020.10.11. 20210773

42 Rauscher E. Lower State COVID-19 Deaths and Cases with Earlier School Closure in the U.S. [Internet]., 2020. Available: https:// medrxiv.org/cgi/content/short/2020.05.09.20096594

43 Sruthi CK, Biswal MR, Joshi H, et al. How Policies on Restaurants, Bars, Nightclubs, Masks, Schools, and Travel Influenced Swiss COVID-19 Reproduction Ratios [Internet]., 2020. Available: https:// medrxiv.org/cgi/content/short/2020.10.11.20210641

44 Stage HB, Shingleton J, Ghosh S, et al. Shut and re-open: the role of schools in the spread of COVID-19 in Europe [Internet], 2020. Available: https://medrxiv.org/cgi/content/short/2020.06.24. 20139634

45 Stein-Zamir C, Abramson N, Shoob H, et al. A large COVID-19 outbreak in a high school 10 days after schools' reopening, Israel, May 2020. Eurosurveillance 2020;25:2001352.

46 Stokes J, Turner AJ, Anselmi L, et al. The relative effects of nonpharmaceutical interventions on early Covid-19 mortality: natural experiment in 130 countries [Internet]., 2020. Available: https:// medrxiv.org/cgi/content/short/2020.10.05.20206888

47 Wu JY, Killeen BD, Nikutta P, et al. Changes in Reproductive Rate of SARS-CoV-2 Due to Non-pharmaceutical Interventions in 1,417 U.S. Counties [Internet]., 2020. Available: https://medrxiv.org/cgi/content/ short/2020.05.31.20118687

48 Yang B, Huang AT, Garcia-Carreras B, et al. Effect of specific nonpharmaceutical intervention policies on SARS-CoV-2 transmission in the counties of the United States [Internet]., 2020. Available: https:// medrxiv.org/cgi/content/short/2020.10.29.20221036

49 Yehya N, Venkataramani A, Harhay MO. Statewide interventions and Covid-19 mortality in the United States: an observational study. Clin Infect Dis 2020. doi:10.1093/cid/ciaa923. [Epub ahead of print: $08 \mathrm{Jul}$ 2020].

50 Zeilinger EL, Nader IW, Jomar D, et al. Onset of effects of nonpharmaceutical interventions on COVID-19 worldwide [Internet] 2020. Available: https://medrxiv.org/cgi/content/short/2020.09.02. 20185660 
51 Wong MC, Huang J, Teoh J, et al. Evaluation on different nonpharmaceutical interventions during COVID-19 pandemic: an analysis of 139 countries. $J$ Infect 2020;81:e70-1.

52 Walach $\mathrm{H}$, Hockertz S. What association do political interventions, environmental and health variables have with the number of Covid-19 cases and deaths? A linear modeling approach [Internet], 2020. Available: https://medrxiv.org/cgi/content/short/2020.06.18.20135012

53 Shah S, Ray B, Holy C, et al. Co3 effectiveness of government measures to reduce COVID-19 mortality across 5 different countries. Value in Health 2020;23:S400-1.

54 Abbott S, Hellewell J, Thompson RN. Estimating the timevarying reproduction number of SARS-CoV-2 using national and subnational case counts [version 2; peer review: 1 approved with reservations].. Wellcome Open Research [Internet] 2020;5 https:// wellcomeopenresearch.org/articles/5-112/v2
55 Lemaitre JC, Perez-Saez J, Azman AS, et al. Assessing the impact of non-pharmaceutical interventions on SARS-CoV-2 transmission in Switzerland. Swiss Med Wkly 2020;150:w20295.

56 Wieland T. Change points in the spread of COVID-19 question the effectiveness of nonpharmaceutical interventions in Germany [Internet], 2020. Available: https://medrxiv.org/cgi/content/short/ 2020.07.05.20146837

57 Varma JK, Thamkittikasem J, Whittemore K, et al. COVID-19 infections among students and staff in New York City public schools. Pediatrics 2021;147:e2021050605.

58 Zimmerman KO, Akinboyo IC, Brookhart MA, et al. Incidence and secondary transmission of SARS-CoV-2 infections in schools. Pediatrics 2021;147:e2020048090. 